\title{
Ionospheric Disturbances Recorded by DEMETER Satellite over Active Volcanoes: From August 2004 to December 2010
}

\author{
Jacques Zlotnicki, ${ }^{1}$ Feng $\mathrm{Li}^{2}{ }^{2}$ and Michel Parrot ${ }^{3}$ \\ ${ }^{1}$ CNRS, UMR6524-OPGC-UPB, avenue des Landais, BP80026, 63177 Aubière Cedex, France \\ ${ }^{2}$ CNES, CNRS, UMR6524-OPGC-UPB, 24 avenue des Landais, 63177 Aubière Cedex, France \\ ${ }^{3}$ Laboratory of Physics and Chemistry of the Environment and of Space, CNRS, 3 avenue de la Recherche Scientifique, \\ 45071 Orléans Cedex 2, France \\ Correspondence should be addressed to Jacques Zlotnicki; jacques.zlotnicki@wanadoo.fr
}

Received 13 May 2013; Revised 5 September 2013; Accepted 9 September 2013

Academic Editor: Bruno Zolesi

Copyright (C) 2013 Jacques Zlotnicki et al. This is an open access article distributed under the Creative Commons Attribution License, which permits unrestricted use, distribution, and reproduction in any medium, provided the original work is properly cited.

\begin{abstract}
The study analyzes electromagnetic data and plasma characteristics in the ionosphere recorded by DEMETER microsatellite over erupting volcanoes during the life of the mission: from August 2004 to December 2010. The time window in which anomalous changes are searched brackets the onset of the eruptive activity from 60 days before to 15 days after the period during which most pre- and posteruptive phenomena are amplified. 73 volcanoes have entered into eruption. For 58 of them, 269 anomalies were found in relation to 89 eruptions. They are distributed in 5 types, similarly to the ones observed above impeding earthquakes. The two main types are electrostatic turbulence (type 1,23.4\%) and electromagnetic emissions (type 2, 69.5\%). The maximum number of types 1 and 2 anomalies is recorded between 30 and 15 days before the surface activity, corresponding to the period of accelerating phenomena. The amount of anomalies seems related to the powerfulness of the eruptions. The appearance seems dependant on the likelihood to release bursts of gases during the preparatory eruptive phase. For the huge centenary October 26, 2010, Merapi (Indonesia) eruption, 9 ionospheric type 2 anomalies appeared before the eruption. They mainly emerge during the mechanical fatigue stage during which microfracturing occurs.
\end{abstract}

\section{Introduction}

The identification of electric and magnetic signals related to earthquakes and volcanic activity has always been a challenge for Science. The long term objectives are (i) to identify consistent and cross-correlated signals related to natural disasters and (ii) to resolve the characteristics of the impending earthquakes (magnitude, location, and occurrence time) and the features of forthcoming volcanic eruptions (type of activity, powerfulness, occurrence time of the burst, and the vanishing surface activity) with a high degree of reliability for mitigating human fatalities and economical disorganization. These targets will contribute to mitigate human fatalities and economical disorganization.

During almost two centuries, only land observations were feasible and a part of them has shown that electric and/or magnetic signals (called hereafter electromagnetic (EM) signals) may occur before earthquakes and volcanic eruptions. But till now, the recognition well in advance of the characteristics of a future disaster with a large degree of confidence is not yet achieved. However, results obtained on active faults and active volcanoes have reached different levels of achievements.

Along with active faults, a number of observations of preseismic electromagnetic anomalies have now been reported on land in a number of reliable cases (i.e., [1-4]). Most of these signals are transient anomalies which appear during a few minutes or less to some days, but the generation of the EM signals [5-12] is still a matter of debate (i.e., [13]). Some long-term anomalies over months to years are mainly interpreted as progressive resistivity changes in the crust (i.e., $[14,15])$ or as piezomagnetic effects $[16,17]$ related to the building-up of a regional stress field. Local transient anomalies of lifetime duration of some days to few minutes are more difficult to record, and the vast coverage of satellite 
observations becomes a suitable means for global earthquake study. Anomalies in the ionosphere were found, as prior to the recent powerful Tohoku EQ in Japan [18-21]. They are interpreted by a lithosphere-atmosphere-ionosphere coupling (i.e., $[22,23]$ ), although the source(s) of the anomalies in the Earth remain unclear.

On volcanoes, it is relatively common to observe slow and weak increasing EM anomalies during months to years prior to an eruptive event with land monitoring networks $[16,24-$ 26]. These time changes may be very small and undetectable over a short time span monitoring. In addition to these smooth anomalies, transient signals, of tens of seconds to hours duration, may appear during the weeks preceding the eruptions [27-30]. These signals accelerate and raise up sharply during magma migration towards the ground surface or before an explosive phase [31]. It is well accepted that longterm changes are due to either piezomagnetic, thermomagnetic, or resistivity changes which are the key mechanisms depending on the type and the dynamical state of the volcano under consideration. Electrokinetic effects which are signals generated by transfer of electric charges carried out by fluid flow may become the preponderant mechanism when an hydrothermal system takes place in the upper part of a volcanic edifice $[25,26,32]$. On most of the volcanoes, transient volcano-EM signals are enhanced during the two months preceding the surface activity, and these phenomena can be investigated with advanced electromagnetic networks (i.e. $[24,30])$.

As for active faults, few volcanoes are well-monitored by dense ground based networks, and satellite missions give the opportunity to develop a global approach for monitoring natural hazards [3, 20, 33-39].

As compared to studies on earthquakes, few researches have been devoted to the detection of volcanic activity by satellites (i.e., [40, 41]). Thanks to DEMETER satellite (http://smsc.cnes.fr/DEMETER/index.htm) essentially dedicated to the monitoring of ionospheric disturbances generated by natural hazards on the Earth, a unique opportunity for studying preeruptive anomalies in the ionosphere linked to volcanic activity was offered. A first attempt was published in [42] which showed that 30 of the 74 eruptions recorded during the period from August 2004 to December 2007 were accompanied by 48 anomalies in the time window of 30 days preceding the onset of surface activity till 15 days after (noted hereafter $[-30 \mathrm{~d},+15 \mathrm{~d}]$ ). In addition, a systematic analysis of data between August 2004 and December 2006 over three volcanoes (Aoba, Ambrym, and Lopevi) has shown that anomalies in the ionosphere only appeared when the volcanoes entered into activity [42].

In this new study enlarged to a time window of $[-60 \mathrm{~d}$, $+15 \mathrm{~d}$ ] around the burst of eruptive events, an extensive examination of anomalies in the ionosphere based on DEMETER data between August 2004 and December 2010 is presented.

\section{Ionospheric Anomalies over the Period from August 2004 to December 2010}

2.1. DEMETER Mission. DEMETER mission was initiated by the National French Spatial Agency (CNES), which has built a series of microsatellites. DEMETER was the first microsatellite, the objectives of which were the analysis of the ionospheric disturbances due to seismic, volcanic and human activities on the Earth, as well as a better knowledge of the ionosphere itself (see http://smsc.cnes.fr/DEMETER/index .htm for more details about the mission). Launched on June 29, 2004, by a Russian rocket, the microsatellite has flown over the Earth along a polar and circular orbit at a mean altitude of $710 \mathrm{~km}$ till December 2005 and at $660 \mathrm{~km}$ later. CNES decided to stop the mission in December 2010. DEMETER satellite has covered $\sim 14$ orbits per day around the Earth and the distance between two successive orbits at the equator was about $2860 \mathrm{~km}$. The rate of a successful operation has been over $99 \%$ during the 6.5 years of surveys.

A three-components magnetometer (IMSC), a set of electric sensors (ICE), a plasma analyzer (IAP), a Langmuir probe (ISL), and a particle detector (IDP) were operating on board the satellite. Details on the characteristics of the different sensors can be found in April 2006 special issue of Planetary and Space Science [43-47].

2.2. Frame of the Dataset. The identification of ionospheric anomalies over active volcanoes was achieved based on the following constraints.

(i) Because most of the transient volcano-electromagnetic signals on land are observed during the two months preceding an eruption (i.e. $[48,49]$ ), the time window on which anomalies in the ionosphere were investigated was framed to 60 days before till 15 days after the onset of the volcanic activity (noted later on $[-60 \mathrm{~d},+15 \mathrm{~d}])$.

(ii) The distance between the volcano and the footprint of the satellite has determined the distance threshold inside which anomalies were searched. It was taken to $500 \mathrm{~km}$ if the Volcanic Explosivity Index (VEI, http://vulcan.wr.usgs.gov/News/ MSH2004/VEI_information.pdf) was less or equal to 1 and $900 \mathrm{~km}$ for VEI above 1 . These limits were supported by previous a work [42] and are confirmed as adequate in this paper.

(iii) A special care was brought to the global magnetic activity on the Earth which can produce ionospheric disturbances being assimilated to signals induced by the volcanic activity. Volcanoes located between $-50^{\circ} \mathrm{S}$ and $+50^{\circ} \mathrm{N}$ were only taken into consideration to avoid natural ionospheric disturbances due to large magnetic activity at high latitudes. In addition, the effect of natural magnetic activity on the appearance of ionospheric anomalies was studied for the three thresholds of the daily Kp indices 30, 20, and 15 (http://wdc.kugi.kyoto-u.ac.jp/kp/index.html).

(iv) When a tectonic earthquake of magnitude $\geq 4.5$ was recorded along the segment of the orbit under consideration, the anomaly was not retained to avoid any confusion. 


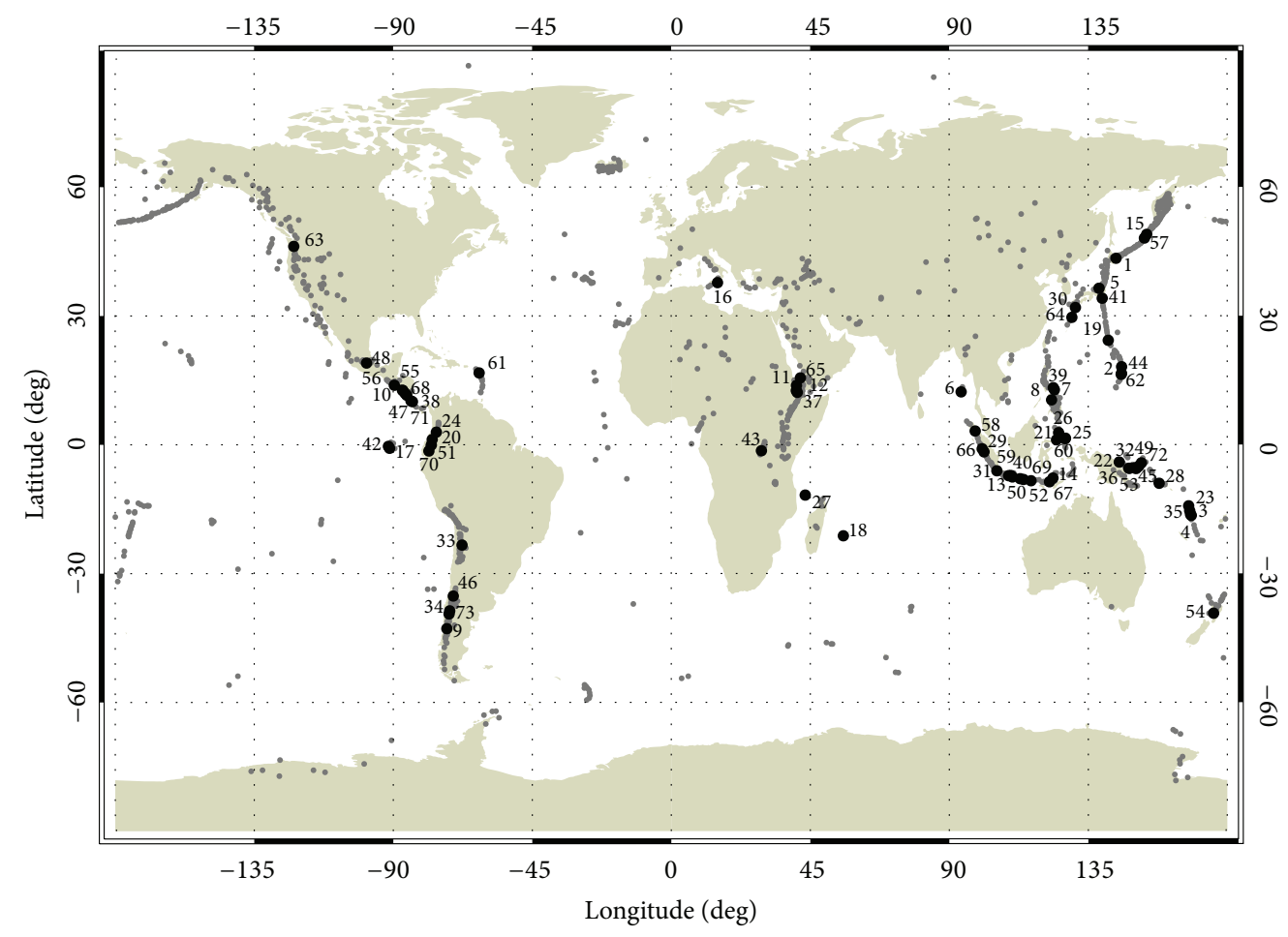

FIGURE 1: Location of active volcanoes. Volcanoes entering into eruption between August 2004 and December 2010 are numbered from 1 to 73.

(v) All upward (south to north) and downward (north to south) orbits in the time window $([-60 \mathrm{~d},+15 \mathrm{~d}])$ were studied.

(vi) Information on the volcanic activity was given by the Global Volcanism program (http://www.volcano .si.edu/).

2.3. Method of Analysis. Between August 2004 and December 2010, 136 eruptions occurred in 73 volcanoes located between latitudes $50^{\circ} \mathrm{S}$ and $50^{\circ} \mathrm{N}$. For each of them, a time window of $[-60 \mathrm{~d},+15 \mathrm{~d}]$ around the onset of volcanic activity was defined. All the orbital segments with a distance to the volcano less than 500 or $900 \mathrm{~km}$ based on the VEI index were computed. Analysis of the records of electric and magnetic fields, ionic and electronic temperatures, and densities was then achieved, and detected anomalies were classified.

Taking into consideration that at least one orbit per day has fulfilled the requirements of the database, about 12,000 orbits were analyzed. It should be noted that for distance thresholds of 500 or $900 \mathrm{~km}$ and the $7.4 \mathrm{~km} / \mathrm{s}$ velocity of the satellite, the interesting part of each orbital segment was limited-at most-to 136 and $244 \mathrm{sec}$, respectively. In addition, the successive shift in the longitude of the satellite $(2860 \mathrm{~km}$ at the equator) has made the recognition of anomalies along two consecutive orbits uneasy. In spite of this unfavourable situation, 269 anomalies were recognized (Figure 1).

2.4. Observations: Five Types of Anomalies. The 269 anomalies can be grouped into 5 types. Examples of the locations of volcanoes and the characteristics of the anomalies in DEMETER records are reported in Figures 2(a), 2(b), 2(c), 2(d), and 2(e).

(i) Anomaly of type 1 is illustrated by the anomaly detected on November 20, 2009, above Poas volcano (Costa Rica, Figures 1 and 2(a)), 35 days before the eruption (December 25, 2009, VEI = 1). The minimum distance of the footprint of the satellite was $90 \mathrm{~km}$. This anomaly is expressed by a higher energetic content of the electric field measured by the electric ICE sensor and a small change in the ionic density. The anomaly of about 15 seconds can be seen over a hundred of kilometres. The frequency domain goes from DC to $250 \mathrm{~Hz}$ with a maximum amplitude positioned at the centre of the anomaly. This type of anomaly is well-known as ionospheric electrostatic turbulence (i.e., [50]). In general, the type 1 anomaly is accompanied by anomalous changes in the electronic and ionic densities and temperatures as well (i.e., on Lascar volcano on April 27, 2004) [42]. 63 anomalies of type 1 of a total of 269 anomalies were recognized $(23.4 \%)$.

(ii) Type 2 anomaly is composed of simultaneous short time duration anomalies in the electric and magnetic fields. The duration of type 2 anomaly can be as short as 1 or 2 seconds and the frequency content, generally less $1,000 \mathrm{~Hz}$, can occasionally reach $2 \times 10^{4} \mathrm{~Hz}$. The maximum energy is positioned around the centre of the frequency band. Type 2 anomaly is in fact composed of whistlers with small dispersion and large 

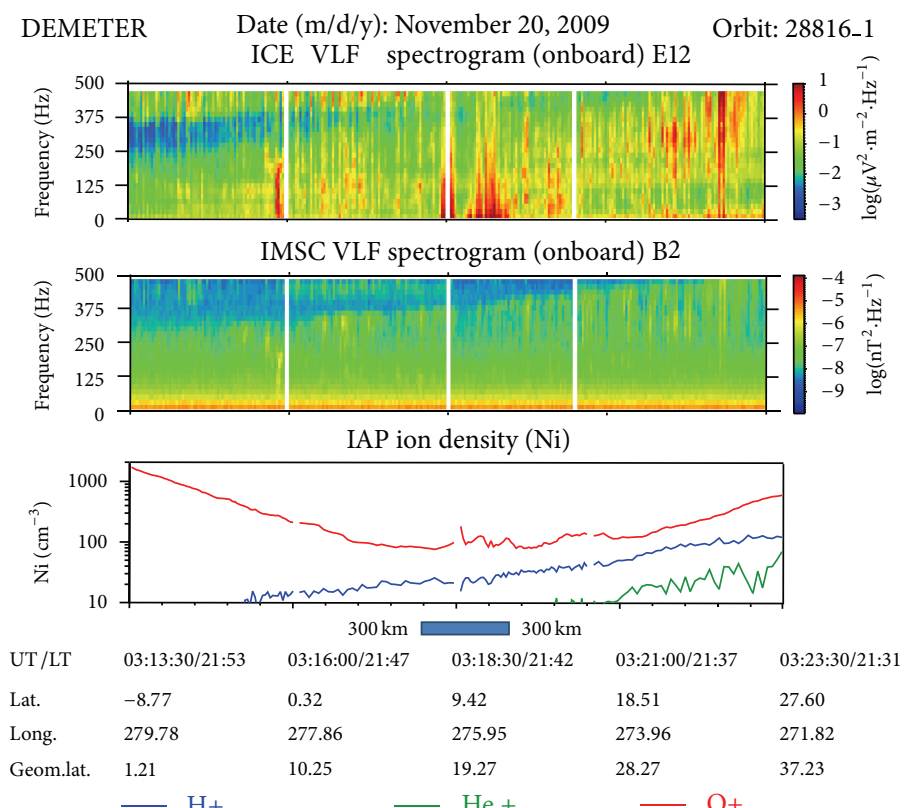

(a)
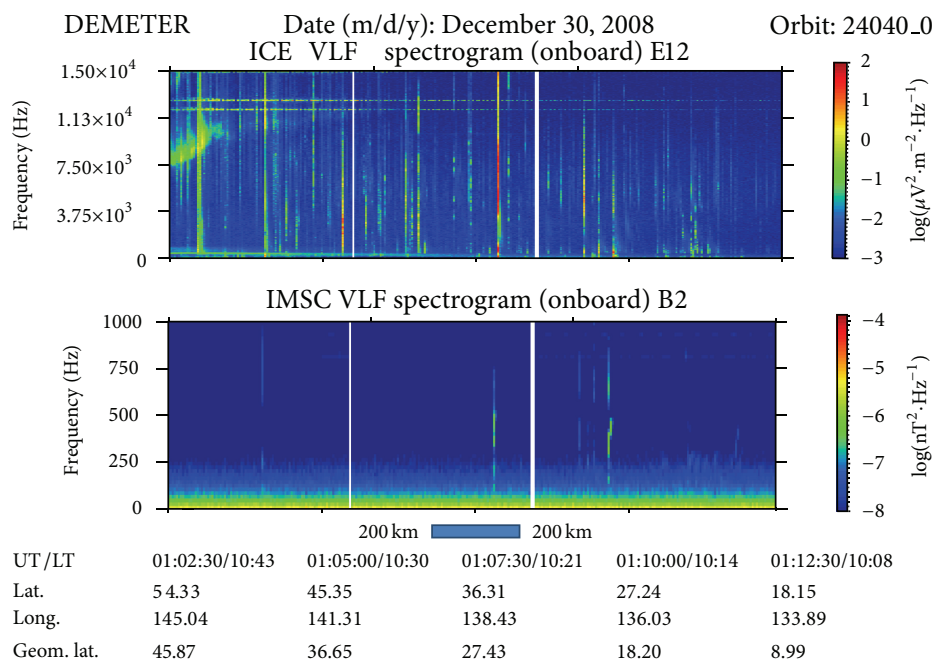

(b)
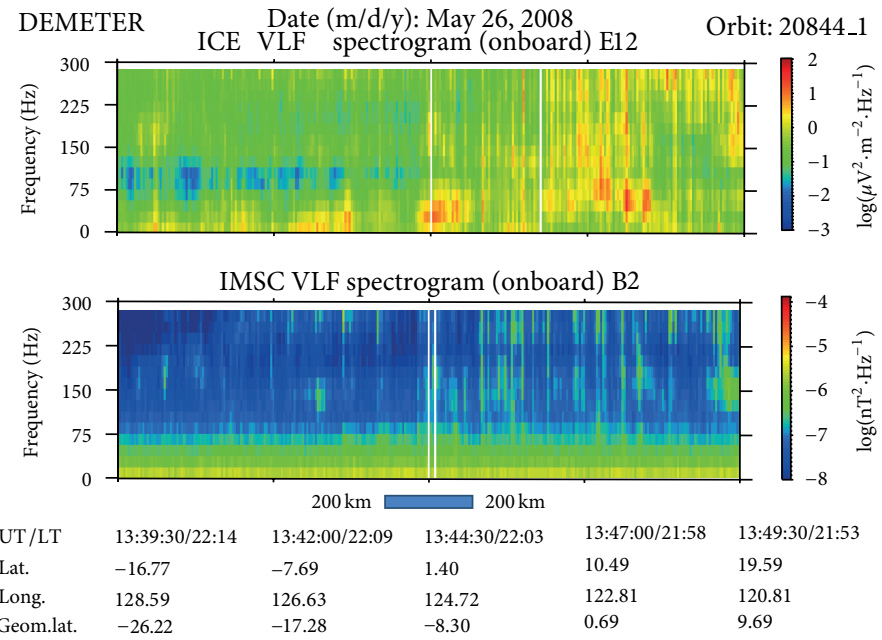

(c)

Figure 2: Continued. 


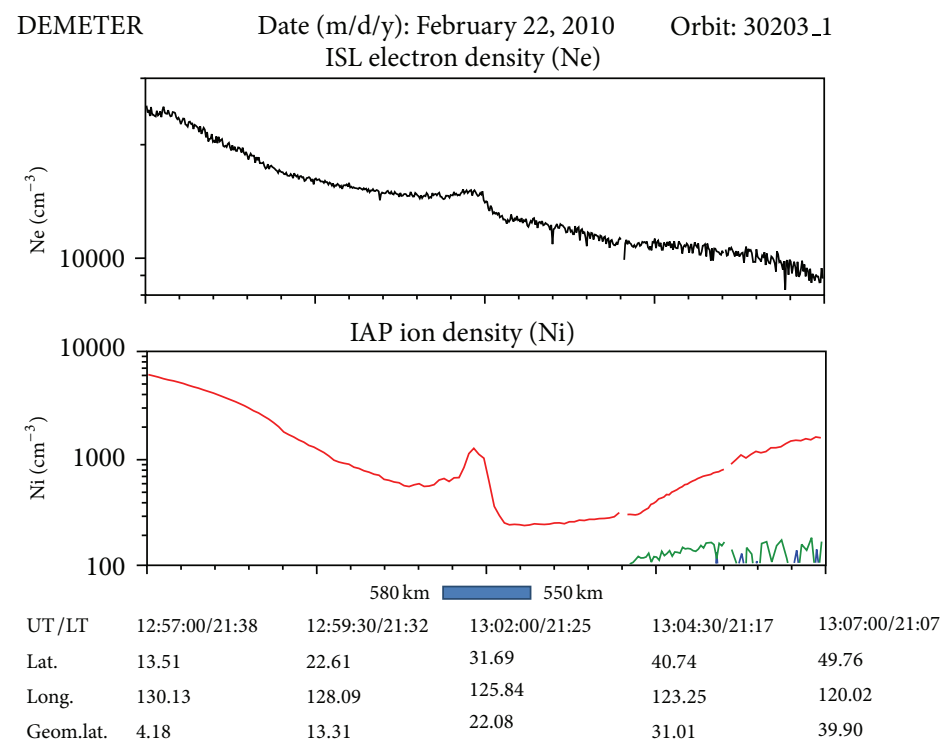

(d)

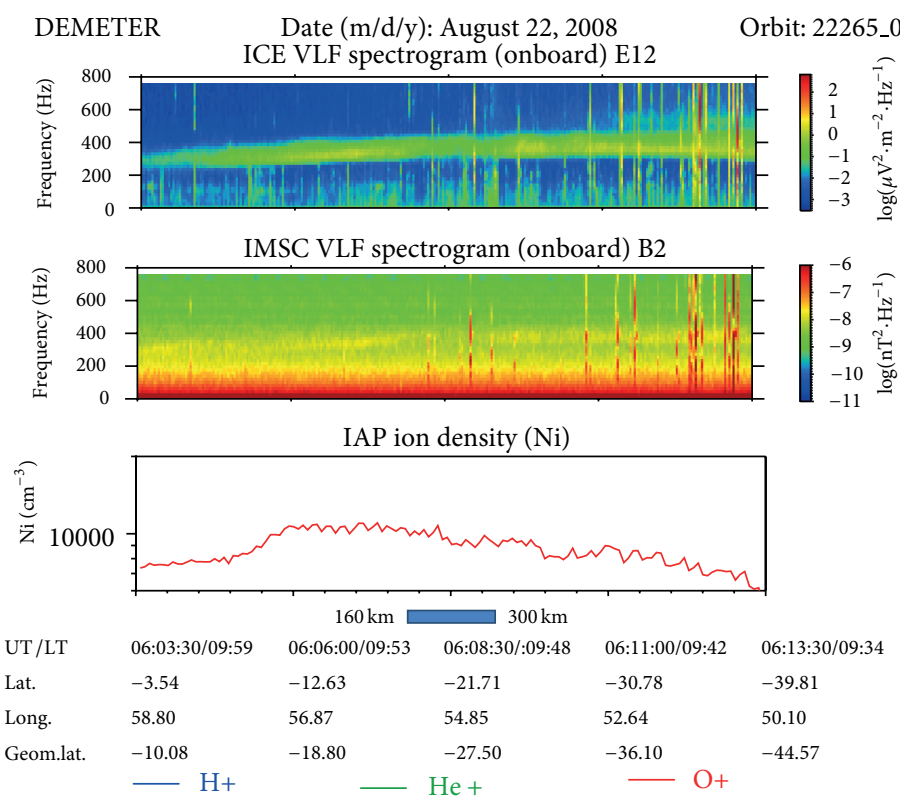

(e)

Figure 2: (a) Example of type 1 anomaly. Electric anomaly recorded on Poas volcano on November 20, 2009, 35 days before the beginning of the eruptive activity. From top to bottom: Spectrogram of the electric field up to $500 \mathrm{~Hz}$ (the intensity is colour-coded according to the scale on the right), spectrogram of the magnetic field up to $500 \mathrm{~Hz}$, and ion densities (H+ in blue, $\mathrm{O}+$ in red, and He+ in green). The closest approach to the volcano is between 03:18:30 $(90 \mathrm{~km})$ and 03:19:30 UT $(120 \mathrm{~km})$. The blue rectangular indicates how the distance of the footprint of the satellite moves. (b) Example of type 2 anomaly. Electric (top panel) and magnetic (bottom panel) anomalies recorded on Asama volcano on December 30,2008, 22 days before the eruption. The electric spectrogram is up to $15 \mathrm{kHz}$, whereas the magnetic one is up to $1 \mathrm{kHz}$. The closest approach to the volcano is at 01:07:30 UT $(15 \mathrm{~km})$. The blue rectangle that indicates how the distance of the footprint of the satellite moves. (c) Example of type 3 anomaly. Time elongated electric anomaly recorded on Soputan volcano on May 26, 2008, 10 days before the onset of surface activity. Electric (top panel) and magnetic (bottom panel) spectrograms are up to $300 \mathrm{~Hz}$. The closest approach to the volcano is at 13:44:30 UT $(35 \mathrm{~km})$. The blue rectangular indicates how the distance of the footprint of the satellite moves. (d) Example of type 4 anomaly. Change in electronic (top panel) and ionic (bottom panel (O+ in red, and He+ in green)) densities recorded on Kirishima volcano on February 22, 2010, 36 days before the surface activity started. The closest approach to the volcano is at 13:02:00 UT (470 km). The blue rectangular indicates how the distance of the footprint of the satellite moves. (e) Example of type 5 anomaly. Decrease of the energy content in the electric and magnetic fields recorded on La Fournaise volcano on August 31, 2008, 21 days before beginning of opening of active fissures. From top to bottom: spectrogram of the electric field up to $800 \mathrm{~Hz}$ (the intensity is colour-coded according to the scale on the right), spectrogram of the magnetic field up to $800 \mathrm{~Hz}$, and the $\mathrm{O}+$ density. The closest approach to the volcano is at 06:08:30 UT $(105 \mathrm{~km})$. The blue rectangular indicates how the distance of the footprint of the satellite moves. 
intensities. This is due to emissions generated in the atmosphere by lightning strokes just below the satellite. When these emissions reached the satellite, the intensity has decreased because they have crossed the ionosphere. But for type 2 anomalies, the emissions are less attenuated because they have crossed a disturbed ionosphere area in the vicinity of the volcano (see discussion in Section 3). Sometimes, electron and ionic densities and temperature anomalies can be associated with the electric and magnetic anomalies (i.e., on Aoba volcano on November 21, 2005) [42]. This type of anomaly is also well-observed above large tectonic earthquakes (i.e., [51]). It is the most representative type of anomaly recorded by DEMETER satellite above volcanoes since 187 anomalies were found (69.5\%). Figures 1 and 2(b) show one anomaly of type 2 on Asama volcano (Japan) happening on December 30, 2008; let it be 22 days before January 21, $2009(\mathrm{VEI}=2)$.

(iii) Anomaly of type 3 is formed by an elongated anomaly with time appearing either on the electric or the magnetic field. This high energetic anomaly which may appear during 2 minutes is restricted to a frequency band between about 50 and $600 \mathrm{~Hz}$. This type of anomaly is similar to the one observed in March 2006 above Gujarat earthquake in India [52]. One should notice that this anomaly type, concentrated in a narrow frequency band, seems to be a dispersive effect generated either by some type 2 anomaly interacting with an existing anomalous layer in the ionosphere or by the enhancement of the EM field above the volcano into an existing anomalous ionospheric layer. Seven anomalies of this type were found during the 6.5 years of records (2.6\%). This type 3 anomaly is depicted by the one observed on Soputan volcano (Indonesia) on May 26, 2008, 10 days before the onset of the activity dated on June 6, 2008 (Figures 1 and 2(c)).

(iv) Type 4 anomaly is defined by a change in the electronic and/or ionic densities and temperatures. A raise in the density is associated with a decrease in the temperature. There is no corresponding effect in the electric or magnetic field. This type of anomaly can last 30 seconds or more. Eight anomalies have been recognized between August 2004 and December 2010 (3\%). Such kind of anomalies can also be found above earthquakes (i.e., [50]). One example is illustrated by Kirishima volcano (Japan) for which an anomaly appeared on February 22, 2010, 36 days before the March 30, 2010 erupting event of VEI equal to 1 (Figures 1 and 2(d)).

(v) The fifth type of anomaly corresponds to a decrease in the energetic content of the electric and (or) magnetic fields. The anomaly stands in a narrow frequency band of a hundred of Hertz at a frequency less than $500 \mathrm{~Hz}$. The duration can be as long as 2 minutes. This anomaly type could involve the opposite mechanism in the one suspected for anomaly type 3. There is no corresponding anomaly in the ionic or electronic parameters. Only 2 anomalies are present in the 6.5year database $(\ll 1 \%)$. One example is given in Figures 1 and 2(e) for La Fournaise volcano (Réunion Island). The anomaly appears on August 31, 2008, for an eruption which begins 21 days later on September 21, 2008 (VEI = 1).

2.5. Analysis. Between August 2004 and December 2010, 73 volcanoes have entered into eruption (Figure 3). For 58 of them, anomalies in the ionosphere were found in the time window starting 60 days before the eruption and ending 15 days after. On these 58 volcanoes, 89 eruptions have occurred and 269 anomalies in total were found, meaning that each eruption was accompanied by 3 ionospheric anomalies, in average.

2.5.1. Ionospheric Anomalies and Volcanic Activity. 10 to 26 eruptions per year have occurred during the 6.5 years of DEMETER mission (Figure 4). The number of anomalies has varied between 5 in the last 6 months of 2004 and 95 in 2010. From 2005 to 2010, between 38\% and 100\% of the eruptions were accompanied by ionospheric anomalies in the time window $[-60 \mathrm{~d},+15 \mathrm{~d}]$. Two features can be outlined. One is that the appearance of anomalies is not enhanced by the global magnetic activity (Figure 4). The largest amounts of anomalies are recorded between 2008 and 2010 when the average level of daily $\mathrm{Kp}$ values is the lowest (http://wdc.kugi.kyoto-u.ac.jp/kp/index.html, see hereafter for this discussion on $\mathrm{Kp}$ index). The second feature is that the number of type 2 anomalies is the only type highly variable with time. From about 10 anomalies per year, the number sharply increases in 2008 and after, reaching 82 in 2010. This result is due to few volcanoes which became very active after 2008 and gave rise to a large number of anomalies prior to their activities (Figure 3). In 2008, 13 anomalies were associated with Mount Etna activity (Sicilia, Italy), 9 with Asama volcano (Japan), and 4 with Garbuna volcano (Papua New Guinea). This phenomenon is emphasized in 2010, when several anomalies are related to the same eruptive activity: 13 anomalies on Mount Etna, 8 on San Cristobal (Nicaragua), 9 on Merapi (Indonesia) and Miyakejima (Japan), 6 on Mayon (Philippines), Kirishima (Japan), and Sarigan (Mariana Islands, USA) volcanoes, and 5 on Tengger caldera (Indonesia) and Planchon Peteroa volcano (Chile). This increase in the number of type 2 anomalies is not recorded for the other types of anomalies which remain at the same average level during the 6.5 years of the experimented.

A detail analysis of the anomalies observed either in the south or north hemisphere shows that they do not appear more frequently during summer when lightnings are more recurrent. This result leads to assume that lightnings are not the primary cause of the ionospheric anomalies.

\subsubsection{Effect of the Earth Magnetic Activity on the Number} of Ionospheric Anomalies. The possibility that anomalies are caused by the global magnetic field activity on the Earth can be estimated by computing the number of ionospheric anomalies above each volcano for different threshold values 


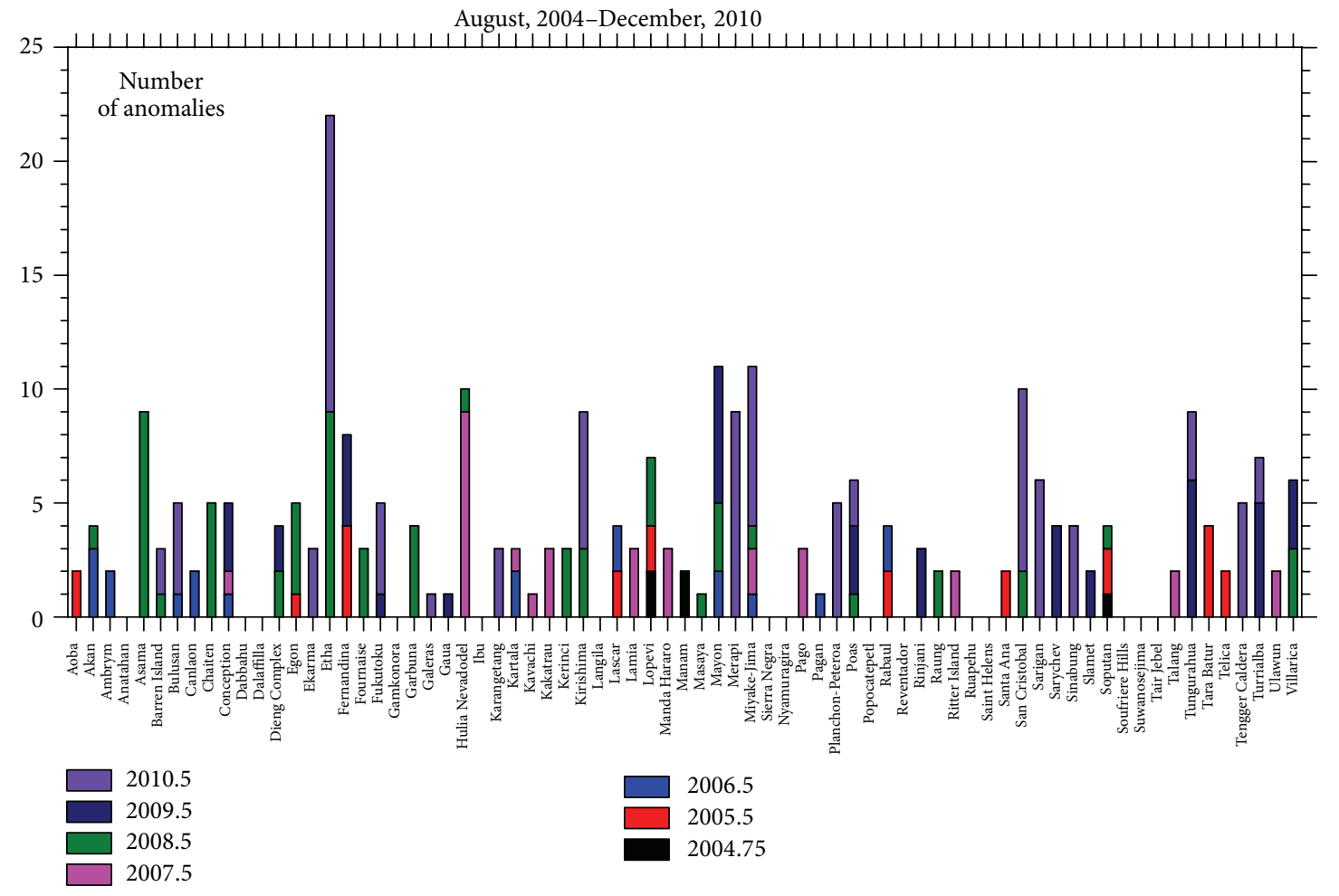

FIGURE 3: Bar chart of the number of anomalies recorded per year for each of the 73 volcanoes which have entered into eruption between August 2004 and December 2010 (note that 2004 data are computed between August and December).

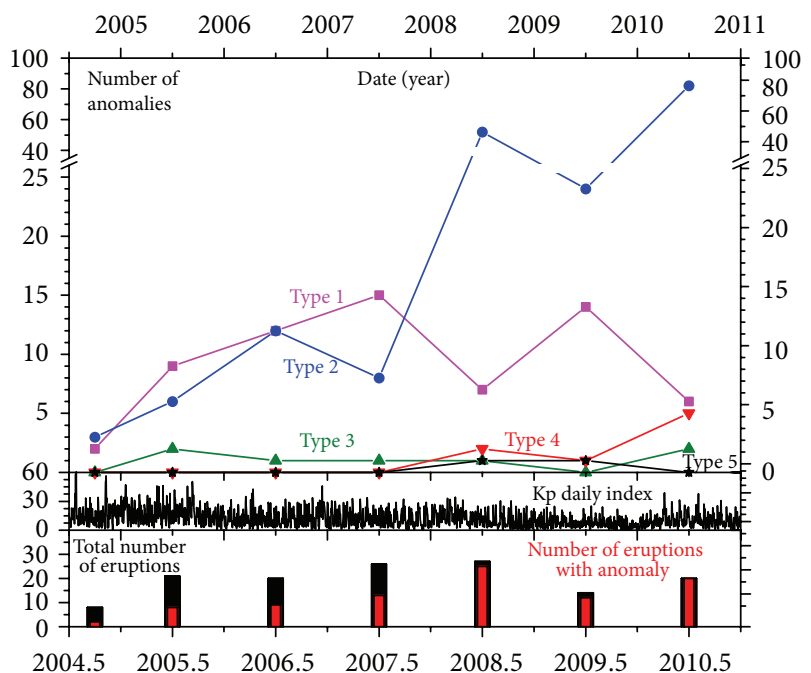

FIGURE 4: Top: number of the 5 types of anomalies per year between mid-2004 and December 2010. Middle: daily mean Kp index versus time. Bottom: bar chart of the number of eruptions having given rise to ionospheric anomalies (red) or not (black).

of the daily Kp index: no restriction on $\mathrm{Kp}$ (noted $\mathrm{Kp}>30$ ), $\mathrm{Kp} \leq 30, \mathrm{Kp} \leq 20$, and $\mathrm{Kp} \leq 10$ (Figure 5). For most of the eruptions, it is remarkable that the number of anomalies does not decrease with the lowering of daily Kp indexes threshold. For Etna volcano on which a large number of type 2 anomalies are recorded, the decays are only $9 \%$ and $27 \%$ when daily Kp thresholds are taken to 20 and 15 as compared to the initial daily $\mathrm{Kp}$ value equal to 30 . For many of the other volcanoes, the number of anomalies remains the same. Therefore, the ionospheric anomalies observed during the period $[-60 \mathrm{~d}$, $+15 \mathrm{~d}$ ] embracing an eruption are not linked to the global magnetic field activity. To go further, the effect of the global magnetic activity can be addressed to the 5 types of anomalies (Figure 6). For none of the different types of anomalies the number of anomalies does not noticeably lessen when the threshold value of $\mathrm{Kp}$ is reduced to half of its original value (i.e., 30 to 15). For type 1 and type 2 anomalies whose amounts are large enough for computing a reliable percentage, the maximum decay is only $27.4 \%$.

2.5.3. Distribution of Ionospheric Anomalies with Time. Figures $7(a)$ and $7(b)$ show the distribution of the percentage of anomalies of types 1 and 2 per 15-day periods during the time window $[-60 \mathrm{~d},+15 \mathrm{~d}]$, respectively. The weak number of anomalies of type 3,4 , and 5 does not allow a reliable time representation. The pattern of the graphs is not significantly distorted when we consider the different threshold values of the daily Kp index ( $>30,30,20$, and 15$)$, demonstrating the consistency of the results. The two graphs clearly illustrate that the maximum number of anomalies whatever the anomaly type is occurs between $[-30 \mathrm{~d},-15 \mathrm{~d}]$ before the eruptive event. This maximum value is gradually decreasing when we consider 15-day time windows more and more in advance of an eruption. As an example, for Kp equal to 30 and 15 , the percentage of the number of anomalies of type 1 is 


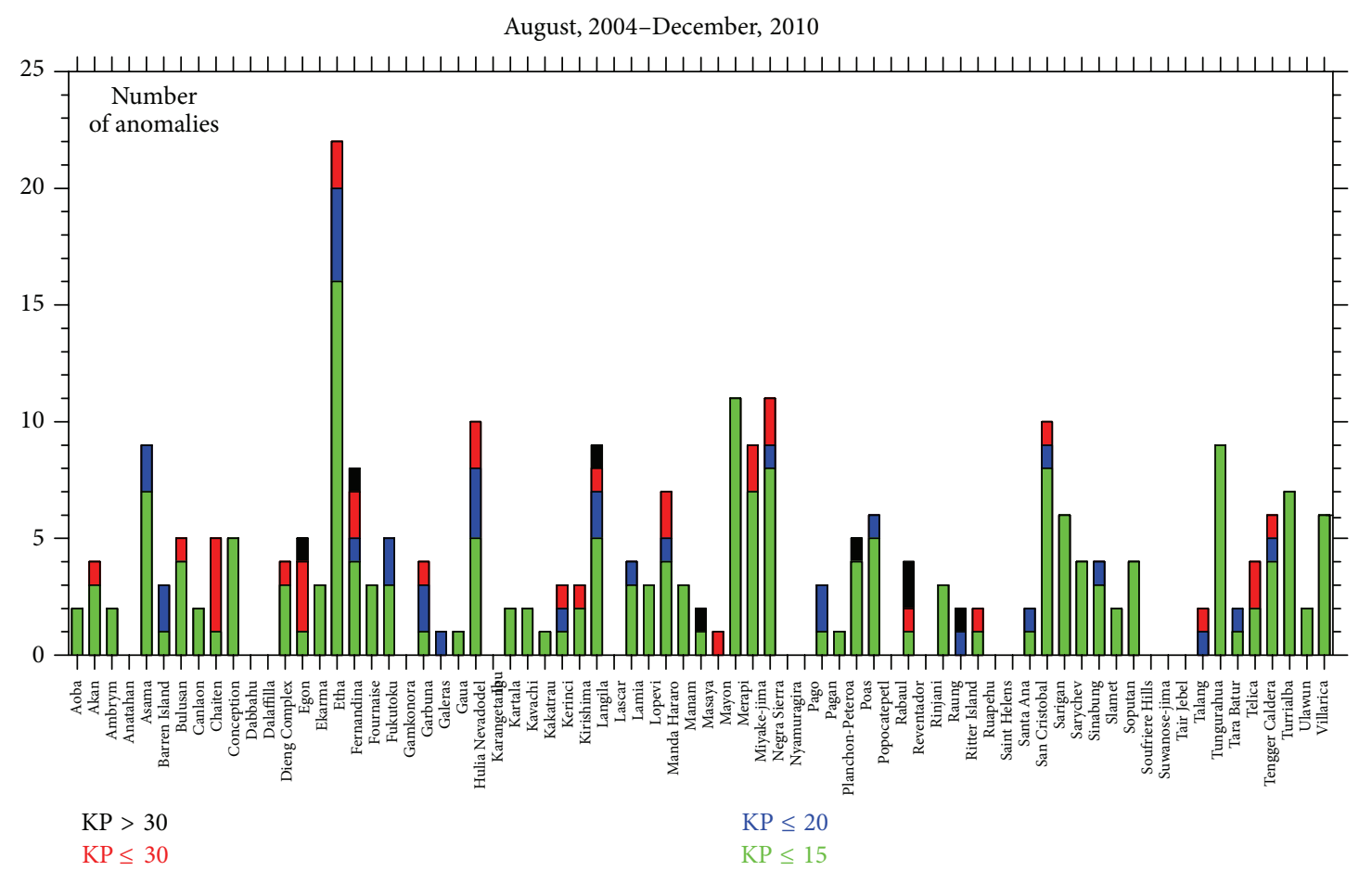

FIGURE 5: Bar chart of the number of anomalies for different threshold values of daily Kp index $(>30, \leq 30, \leq 20$, and $\leq 15)$ recorded per year for each of the 73 volcanoes which have entered into eruption between August 2004 and December 2010.

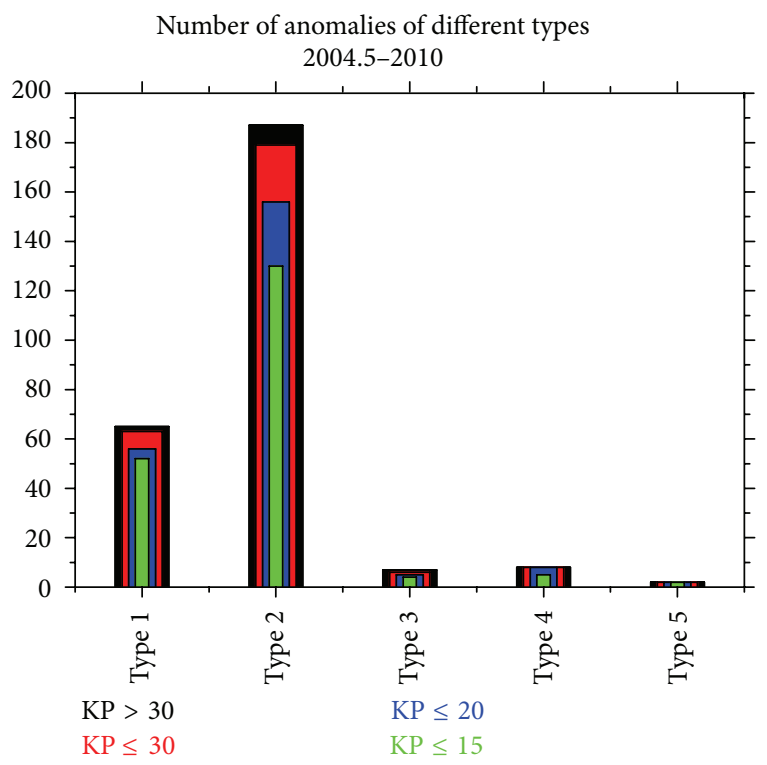

FIGURE 6: Number of the 5 types of anomalies for different threshold values of daily Kp index $(>30, \leq 30, \leq 20$, and $\leq 15)$.

reduced to $56 \%$ and $72 \%$ when the fifteen-day time window shifts from $[-30 \mathrm{~d},-15 \mathrm{~d}]$ to $[-60 \mathrm{~d},-45 \mathrm{~d}]$, respectively. Similarly, the percentage of the number of anomalies of type 2 is lowering to $21 \%$ and $40 \%$. In summary, when anomalies of type 1 or 2 come out before an eruptive event, they essentially appear in the 60 days preceding the onset of activity and the largest probability to observe an anomaly stands in the period
[ $-30 \mathrm{~d},-15 \mathrm{~d}$ ] before the eruptive event. During the 15 days before an eruption, the attenuation of type 1 anomalies reaches $44 \%$ and $56 \%$ for Kp equal to 30 and 15, respectively. Correspondingly, the attenuation of anomalies of type 2 is $24 \%$ and $40 \%$ for Kp equal to 30 and 15, respectively. On the other hand, ionospheric anomalies can still be observed-at least-during the beginning of the eruptive activity.

\section{Discussion}

Between August 2004 and December 2010 more than 20,000 orbits above active volcanoes have been analyzed during a time window of 60 days before an eruption to 15 days after. The results confirm those obtained by a systematic investigation of ionospheric anomalies over three particular volcanoes (Ambrym, Aoba, and Lopevi) during the period from August 2004 to December 2006 [42]. Electric, magnetic, ionic, and electronic temperatures and densities anomalies may appear in the last months before volcanic eruptions.

In the considered database, 73 volcanoes have entered into activity, and 58 of them have given rise to anomalies in the ionosphere. 89 eruptions of a total of 136 (i.e., $65.4 \%)$ were accompanied by ionospheric anomalies. The 269 anomalies are distributed in 5 types, which are to some extent documented above large earthquakes [50-53]. Let us recall that this number of anomalies is most surely the minimum of anomalies which have occurred on these volcanoes, because DEMETER satellite was only "opened eyes" during at most $244 \mathrm{sec}(900 \mathrm{~km}$ threshold distance for VEI $\geq 1)$ along one orbit. DEMETER satellite was unfortunately stopped 


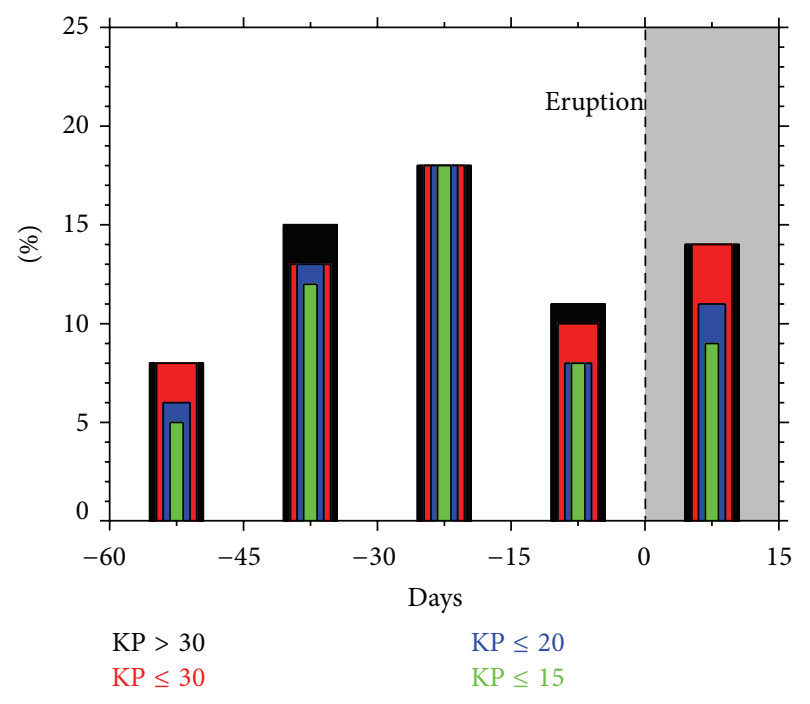

(a)

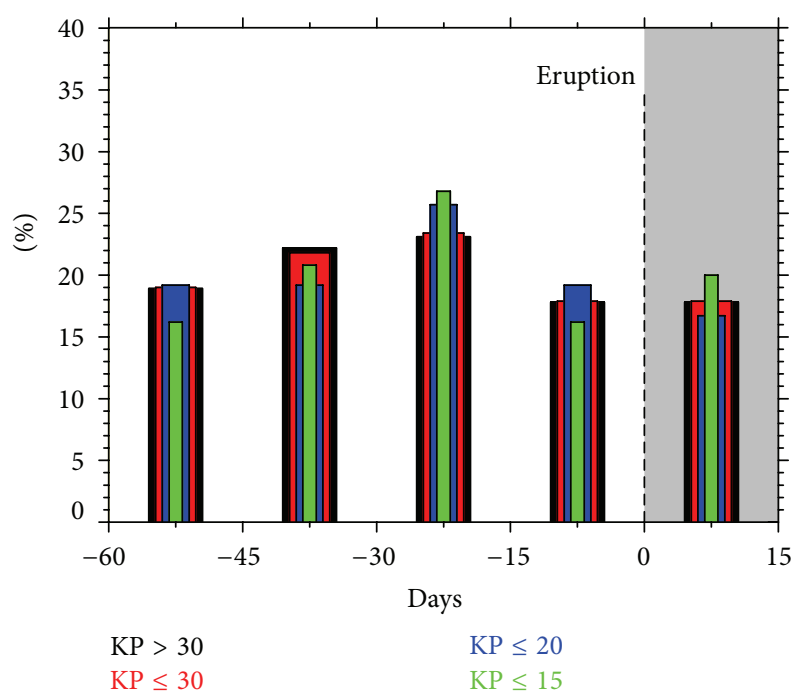

(b)

FIgURe 7: (a) Percentage of type 1 anomalies by 15-day periods between 60 days before the onset of eruptive activity and 15 days after. (b) Percentage of type 2 anomalies by 15 -day periods between 60 days before the onset of eruptive activity and 15 days after.

in December 2010 and consequently the database remains undersized as compared to the database related to tectonic earthquakes of magnitude above 4.5 [10]. Subsequently, the number of anomalies and the probability values obtained in this study could slightly change with a longer period of data collection based on continuous satellite observations.

The most common types of anomalies above active volcanoes are electrostatic disturbances (type 1) and discrete electromagnetic emissions (type 2). They represent $24.4 \%$ and $69.4 \%$ of anomalies when we consider a threshold value of 30 for daily Kp index. For these two types of anomalies, the maximum probability of occurrence is between 30 days and 15 days before the beginning of the eruptions. The main question pointed out by these results is the generation of ionospheric anomalies in the weeks prior to an eruption or during this one. Let us discuss this critical point.

The preliminary remark is that DEMETER satellite was effective for detecting ionospheric anomalies by comparing the background noise level of the parameters (ICE, IMSC, ISL, IAP, etc.) with an enhanced signal when the satellite was flying only nearby a volcano. In the case of low and continuous volcanic reactivation over years, as a regional increase of the stress field or a raise of deep thermal activity in a magma reservoir, successive orbits of the satellite have shown the inability to detect such small rate changes in the activity. On the other hand, taking into account that only few examples of anomalies were recorded along consecutive orbits, it means that mainly transient ionospheric signals of about one day's duration or less were produced (or detected) in the ionosphere. Only these types of high energetic transient signals could have been recorded by the satellite.

These statements lead to analyze the transient or steplike changes which can arise in the environment of volcanic systems in the weeks preceding an eruptive event. Each volcano has its own eruptive behaviour which depends on the regional tectonic setting, the present day structural feature, the magma feeding system and its chemical composition, the presence of an active hydrothermal system, and the effect of the climatic environment. However, it appears that one may schematically describe a forerunner activity as follows.

Mainly, one may consider two kinds of volcanic unrests. The first behaviour is representative of volcanoes which are the seat of low raise of mechanical, thermo- or hydrodynamical processes over months to years which-only-sharply increases when the eruptive process leading to surface activity is engaged: mechanical failure of the edifice by injection of upward magma, disruption in the equilibrium of the hydrothermal state, or gas release during rockfracturing, for instance. Noticeable raise of seismicity, evident ground deformations, and large increase of degassing appear in the very last stage of the preeruptive activity, say, some hours to a few days. Such eruptions can be figured out by the 1986 Izu Oshima eruption [24, 54], the 2000 Miyake-jima (i.e., [32]), the 2000 Usu eruption [55], and the 1959 to 2000 Kilauea eruptions [56]. The second behaviour of activity can generally be summarized by an abrupt boost of seismicity, a coherent speed-up raise of ground deformations, and a powerful discharge of gases during days to weeks before the eruption (i.e., St. Helens [57], Merapi [58-60]).

Before the very few weeks preeruptive period of dynamical processes, characterised by acceleration of strain and rupture phenomena leading to an eruptive event, volcanoes are often submitted to a continuous background activity over months to years caused by releases of heat, movement of ground water, degassing of volatiles, stresses from regional tectonics, tides, and other forcing actions [48]. The long action of these phenomena progressively weakens the mechanical cohesion of the materials constituting the upper part of volcanoes. It drastically lowers the mechanical threshold above which cracks or fissures may reopen. This regime of loss of cohesion and cracks growth, corresponding to the well-known mechanical fatigue stage $[49,61,62]$, is related to opening or reopening of small 


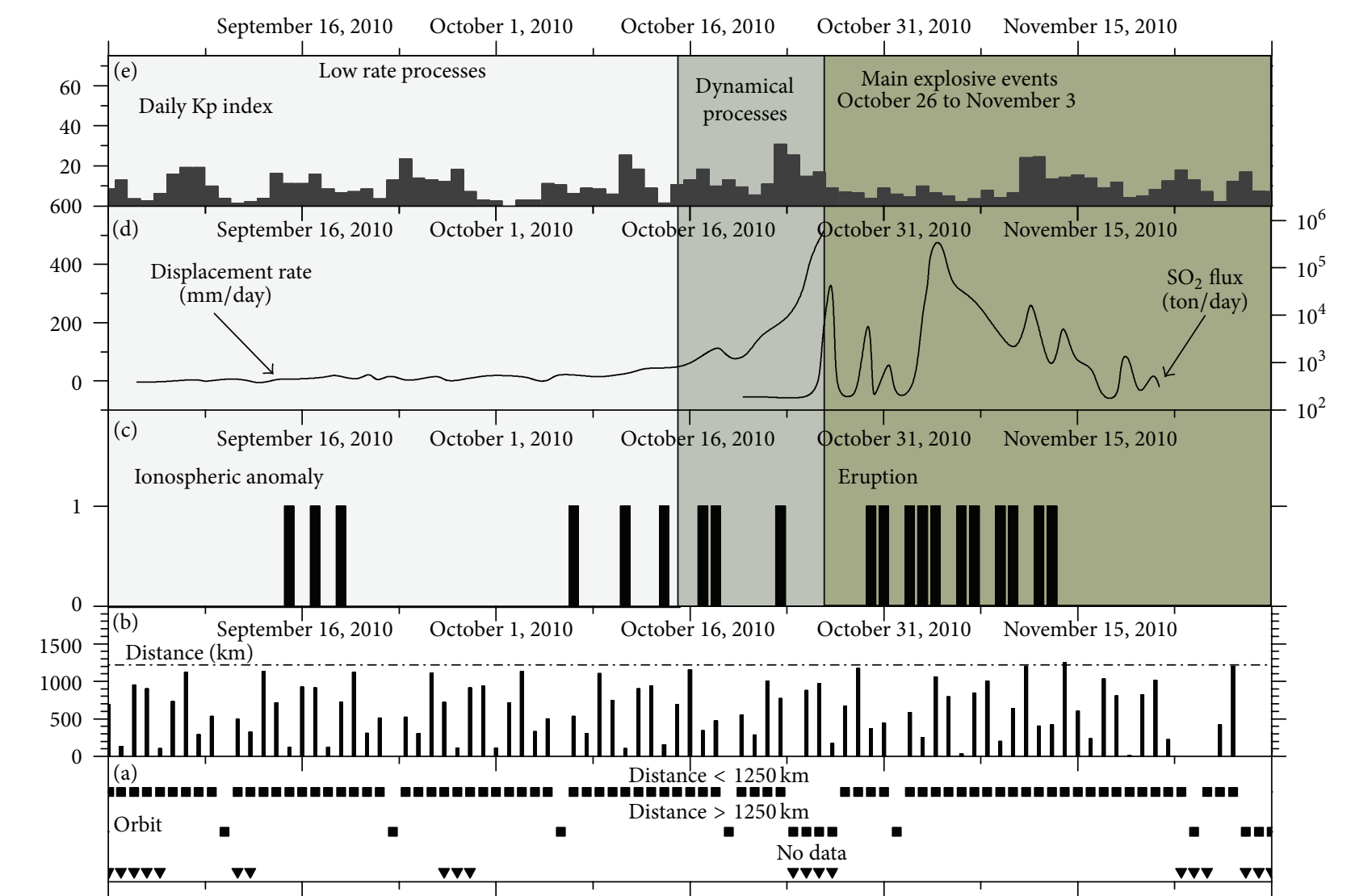

September 1,2010 September 16, 2010 October 1,2010 October 16, $2010 \quad$ October 31,2010 November 15, 2010 November 30, 2010

FIGURE 8: Ionospheric anomalies recorded during the period from September 1 to November 30, 2010, and related to the October 26 eruption of Merapi volcano. (a) Available nighttime DEMETER orbits and distance between the satellite footprint and the volcano; no data available are drawn with downwards black triangles. (b) Distance between the satellite and the volcano. (c) Recognised ionospheric anomalies. (d) Daily displacement rate on the southern flank of the volcano and $\mathrm{SO}_{2}$ flux discharge (following Surono et al., 2012). (e) Daily Kp index and synthetic activity. Light grey rectangle corresponds to the end of the mechanical fatigue period, medium grey rectangle fits to the dynamical processes period, and dark grey rectangle matches with the beginning of the surface activity.

vertical 1-10 mm long cracks over 10 to $100 \mathrm{~m}$ distances along magmatic pathways carrying gas and fluids $[49,63]$. This phenomenon is amplified by existing high temperature which favours chemical interactions. Therefore, opening of fissures and mechanical readjustments appear along any weakened geologic structures as crater or caldera rim, corridors of pyroclastic flows, adjacent geothermal fields or fumarolic areas, regional faults, and so forth. These remarks lead to suppose that bursts of short time duration of gas release, heat fluxes, and electric fields may predominantly appear during the enhancement of the mechanical fatigue stage which takes place before the very few weeks duration (let us say 15 days) of dynamical processes preceding the surface activity [64]. Most of DEMETER anomalies found in this study appear during this period of mechanical fatigue period or at the beginning of the dynamical stage leading to an eruptive activity.

To evaluate this assumption, we have considered the case of Merapi volcano in Indonesia (latitude: $7.54^{\circ} \mathrm{S}$, longitude: $110.44^{\circ} \mathrm{E}$, and altitude $2968 \mathrm{~m}$ ) which has entered into a huge eruption of VEI equal to 4 on October 26, 2010. The volcano was well-monitored by ground networks and the description of the activity is well-related in [60] (Figure 8). We processed all upward DEMETER orbits recorded during nighttime between September 1 and November 30, 2010, extending the threshold distance between the footprint of the satellite and the volcano to about $1250 \mathrm{~km}$, considering this powerful 100year event. Seismicity started to slowly increase on September 12 and sharply raised up after October 15 [60]. The distance between a summit benchmark and a southern low altitude one indicated a speed-up of the displacement rate after October 15. This date delimits the low increasing amplitude phenomena period from the dynamical rupture processes occurring just later. After the beginning of the eruption on October 26, large volumes of $\mathrm{SO}_{2}$ were emitted until November 15 [60] (Figure 8). Significant volumes of gas travelled in the atmosphere at an altitude of $15 \mathrm{~km}$ to the west of Australia and the Indian Ocean (http://www.volcano.si.edu/world/ volcano.cfm?vnum $=0603-25=\&$ volpage $=$ var $/$ ). During the first two weeks of November ash plumes also rose up to $18 \mathrm{~km}$ in altitude and dense ashes were observed till distances of $240 \mathrm{~km}$ from the volcano. After November 10, seismicity and gas emission were recovering low levels. Furthermore, Figure 8 shows the upward orbits for which anomalies in 
the ionosphere can be looked for. Twenty anomalies were recognized during the 3-month period, and the distribution of these anomalies is remarkable. The first three anomalies appeared when the low seismicity began around September 12. Then a train of six anomalies were concomitant with the period of weak seismicity and low amplitude displacements (corresponding to the static fatigue mechanical period in $[49,61,62])$. Three anomalies came out during the dynamical process stage. And finally, eleven anomalies were recorded during large emissions of $\mathrm{SO}_{2}$ gas and consequent expel of ash plumes. When the volcanic activity receded, no more ionospheric anomaly was recorded. During the 3 months of records, the daily $\mathrm{Kp}$ index remains low, and 17 ionospheric anomalies related to the volcanic activity of a total of 20 are observed for $\mathrm{Kp} \leq 20$, excluding an artefact due to global magnetic activity on the Earth.

The anomalies in the ionosphere associated with Merapi activity are of type 2 . Figure 9 presents 4 examples of anomalies recorded (a) at the early beginning of the raise of low seismicity, (b) at the ending period of the mechanical fatigue process, (c) during the dynamical rupture process, and (d) during the large period of $\mathrm{SO}_{2}$ and ash plumes dissemination in the atmosphere. All the anomalies exhibit the strongest amplitude around the nearest distance between the footprint of DEMETER and the volcano. Before the burst of surface activity on October 26, the shape of anomalies (a, b, and c) is similar to a nondispersive whistler, while the last anomaly (d) is spreading over large distances. The outsized spatial distribution of this last anomaly could well correspond to the dispersal of gases and ashes in the upper atmosphere over distances of several hundred kilometres. The sequence of anomalies over Merapi volcano should therefore be divided in two clusters, one corresponding to the 9 anomalies observed before the eruption, and the 11 recorded when large explosive events have expelled large amounts of gas and ashes. And, their genesis could have different sources.

Before the eruption, multiphase seismic events corresponding to magma displacement and volcano-tectonic earthquakes related to rock fracturing in the edifice weakly increased till mid-October. During this period, release of $\mathrm{SO}_{2}$ fluxes reached high levels comparable to the previous 1992-2007 eruptive events [60]. The literature does not report big thermal anomalies or large changes in the ground electric field during this period. This observation would suggest that, on Merapi volcano, the ionospheric anomalies occurring before October 26 would mainly take their source in the interaction between gas releases during low-fracturing processes and the atmosphere.

After October 26, the number of ionospheric anomalies is well-correlated with huge gas fluxes escaping from the volcano. The anomalies are intense and widely spread over large distances and directions depending on the atmospheric winds. These DEMETER anomalies should be related to $\mathrm{SO}_{2}$ dispersion as well as to ash clouds which could electrically interact with the atmosphere (i.e., [65]).

The study of the 2010 Merapi eruption highlights key points in the understanding of the genesis of ionospheric anomalies above volcanoes. Anomalies may undoubtedly appear in the time window of about 2 months to few weeks prior to an eruptive event. They may come out before the dynamical processes during which magma flows upwards or irreversible rock fracturing allows violent gas release and explosive activity. Before this phase of escalating processes, the mechanical fatigue period generates microfracturing along vertical potential magma pathways, and discharges of gases confined in overloaded pockets. These transient gas releases preferentially take place along geologic interfaces and geothermal fields as described before. These gas discharges might be accompanied by thermal anomalies and induced ground electric fields. The consequence of this hypothesis would suggest that one source of ionospheric anomalies may come from transient gas discharges associated or not with heat fluxes. Although disturbances of the atmospheric electric field produced by large electrokinetic signals in the ground prior to volcanic eruptions have been often reported, this contribution to the formation of ionospheric anomalies cannot yet be estimated. If we refer to Figure 3, all volcanoes, except Sarigan, for which the number of DEMETER anomalies was over 5, were the seat of strong and large volume of $\mathrm{SO}_{2}$ degassing or great thermal anomalies (http://www.volcano.si.edu/index.cfm/).

Many authors suggest different hypotheses based on gas discharges (Radon), heat fluxes, electrification of rocks, gravity waves, and so forth, for analyzing the transfer of anomalies from the ground to the ionosphere $[11,12,66$, 67]. Reported anomalies on Merapi volcano could contribute to more accurate interpretations either above volcanoes or earthquakes.

Finally, the noticeable number of ionospheric anomalies occurring during Merapi eruption allows drawing their spatial distribution versus the distance between the footprint of the satellite and the volcano (Figure 10). It clearly shows that $60 \%$ of the anomalies are observed in a radius of $500 \mathrm{~km}$ around the volcano while $95 \%$ of them are recognized by DEMETER for a threshold distance of $1000 \mathrm{~km}$. This result completely validates the threshold distance of $900 \mathrm{~km}$ taken in the database for moderate eruptions.

DEMETER anomalies have been recorded on a large panel of volcanoes. They can be small or large size islanded volcanoes (i.e., Ambrym, Aoba, Kakatrau, Kerinci, Etna, and Miyake-jima), and others may be huge and high stratovolcanoes (i.e., Huila Nevadodel, Planchon Peteroa, Merapi, and Lascar). These edifices can produce effusive and basaltic lava flows (i.e., Etna, Fernandina, La Fournaise, and Kartala), but most of them exhibit explosive activity with andesitic to dacitic products, strombolian to pyroclastic (i.e., Lascar, Merapi, and Mayon), and even plinian (i.e., Asama and Villarica) eruptive phases. Many of these volcanoes may expel large high altitude ash plumes during their eruptive phase (i.e., Soputan $(2008,13.7 \mathrm{~km}$ high plume), Chaiten (2008, $7 \mathrm{~km})$, Egon $(2008,4 \mathrm{~km})$, Planchon Peteroa (2010, $6.1 \mathrm{~km})$, Sinabung $(2010,5 \mathrm{~km})$, Tungurahua $(2008,14.3 \mathrm{~km})$, and Villarica $(2010,4.7 \mathrm{~km})$ ) (see reports on http://www.volcano.si.edu/), while some others present a moderate activity (i.e., Akan, Garbuna group, Poas, and Santa Ana).

The wide variety of the numerous observations done in this paper suggests that ionospheric anomalies could be more 
ICE VLF spectrogram (onboard) E12

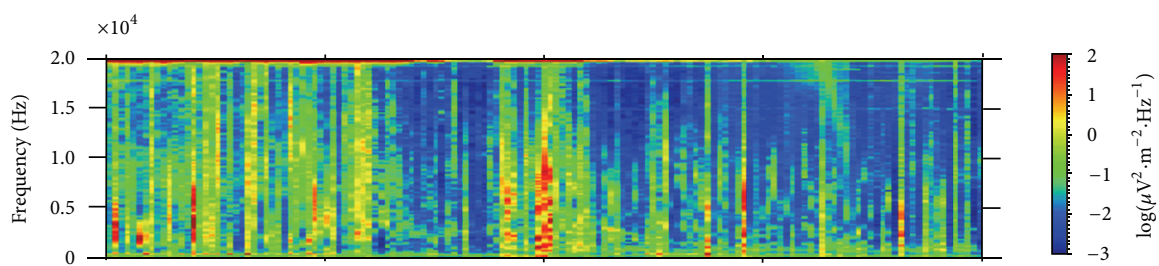

IMSC VLF spectrogram (onboard) B2

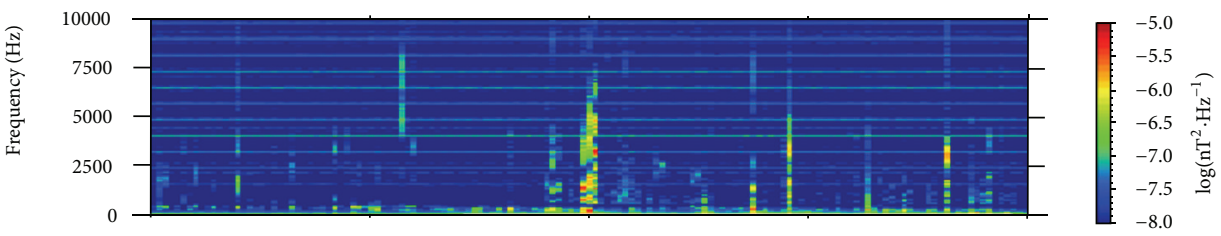

IAP ion density $(\mathrm{Ni})$

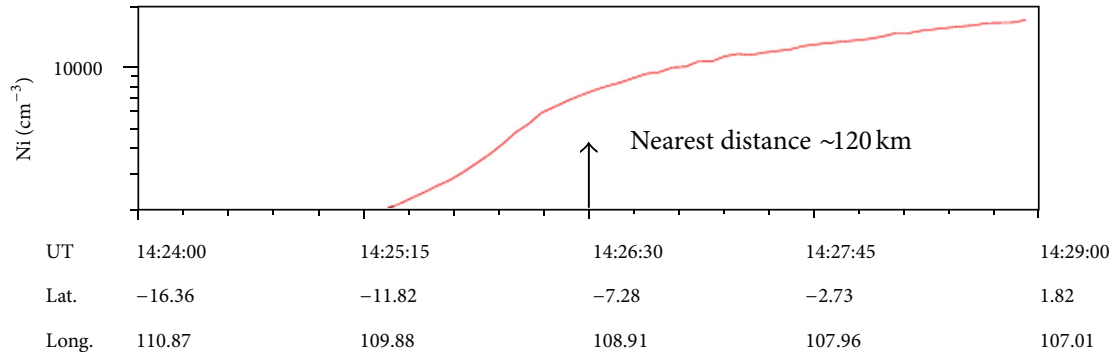

(a)

DEMETER

Date (m/d/y): October 11, 2010

Orbit: $33598 \_1$

ICE VLF spectrogram (onboard) E12

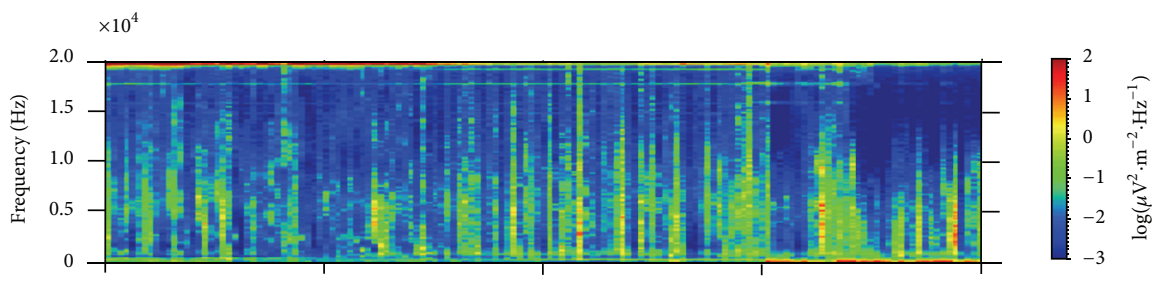

IMSC VLF spectrogram (onboard) B2

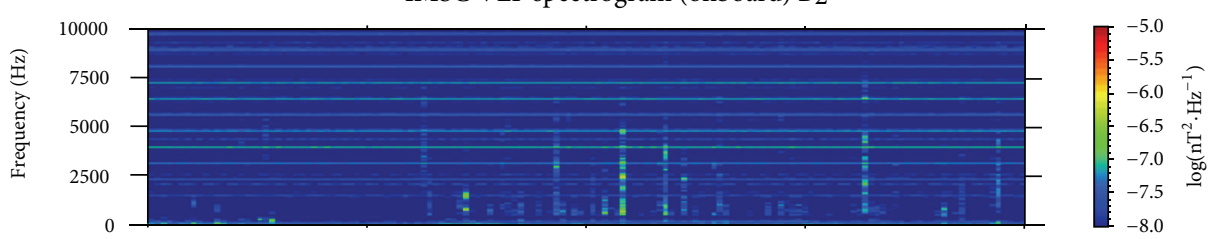

IAP ion density $(\mathrm{Ni})$

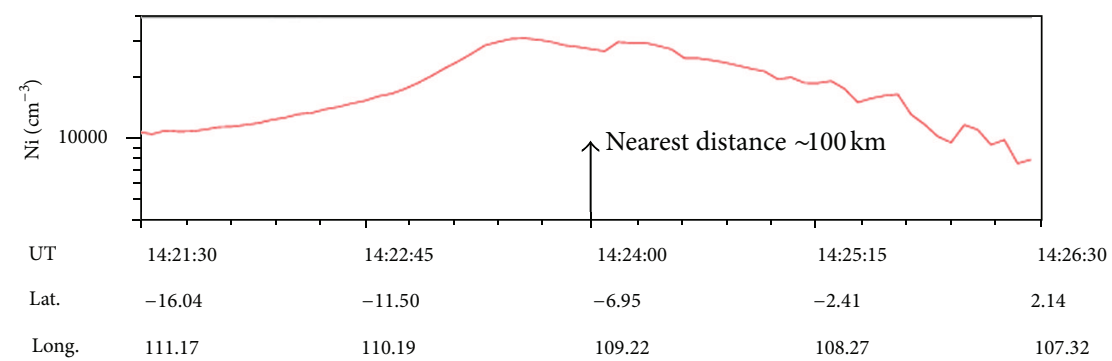

(b)

Figure 9: Continued. 
DEMETER

Date $(\mathrm{m} / \mathrm{d} / \mathrm{y})$ : October 23, 2010

Orbit: 33774_1

ICE VLF spectrogram (onboard) E12
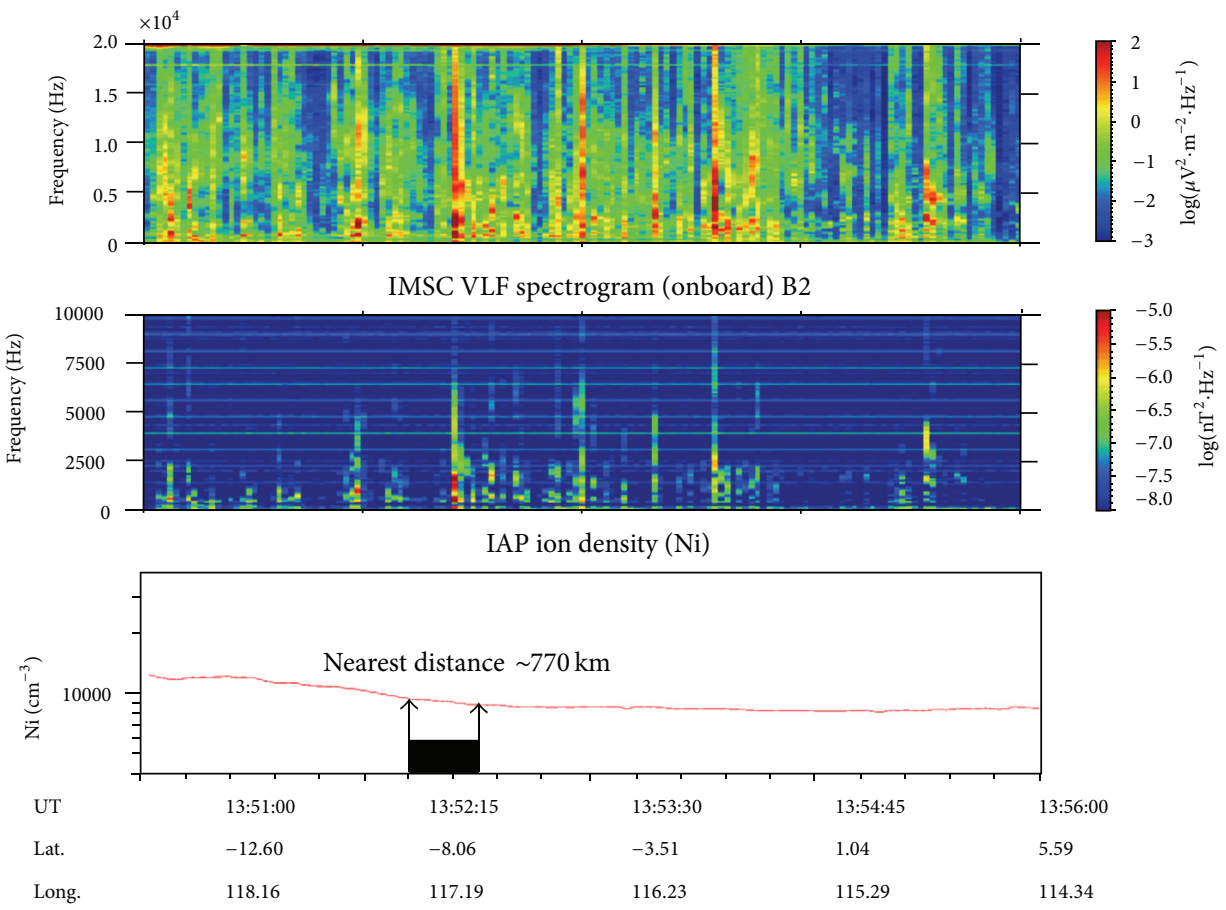

(c)

DEMETER Date $(\mathrm{m} / \mathrm{d} / \mathrm{y})$ : November 13, 2010

Orbit: $34083 \_1$

ICE VLF spectrogram (onboard) E12

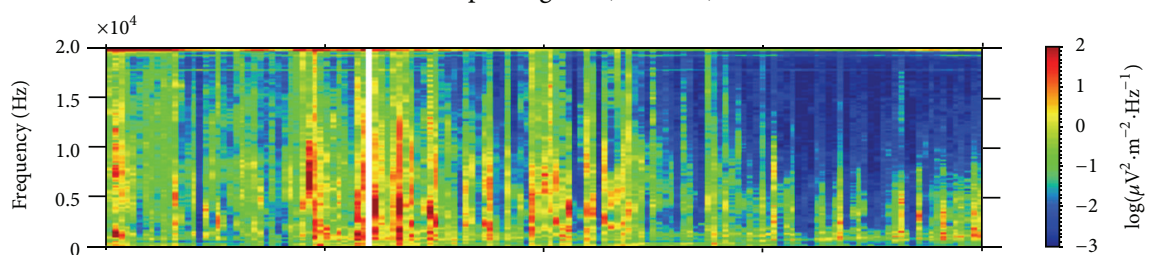

IMSC VLF spectrogram (onboard) B2
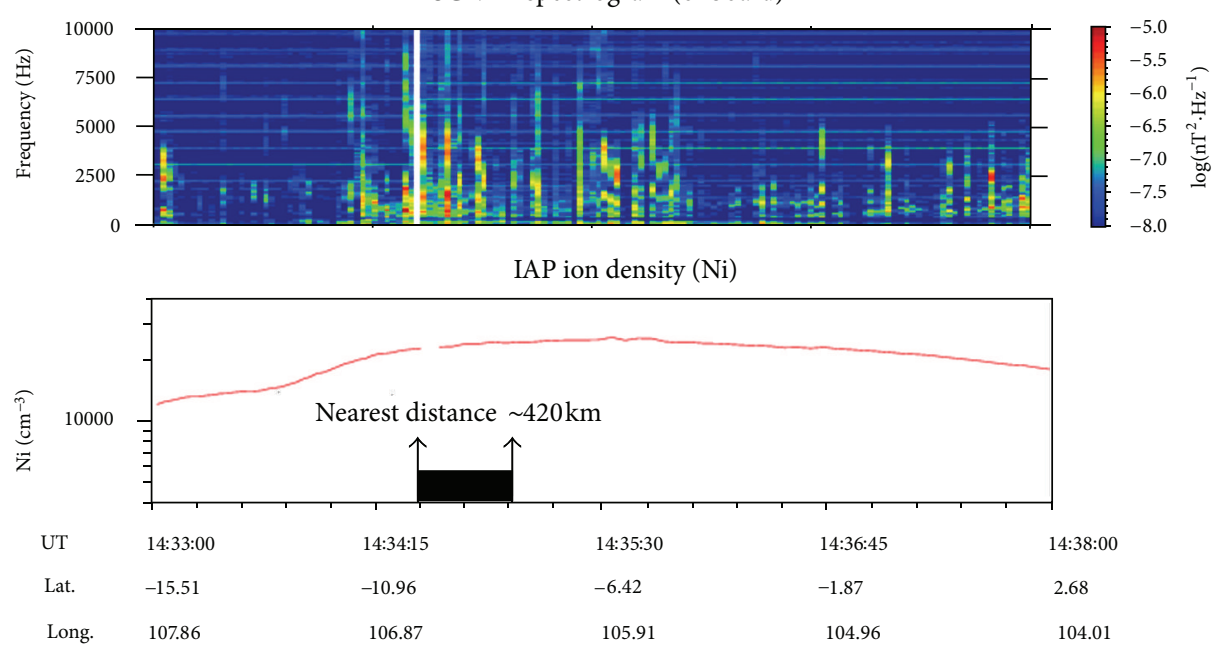

(d)

FIGURE 9: Examples of ionospheric anomalies (electric and magnetic fields and ion density) related to Merapi October 26, 2010, eruption. (a) September 15. (b) October 11. (c) October 23. (d) November 13. 


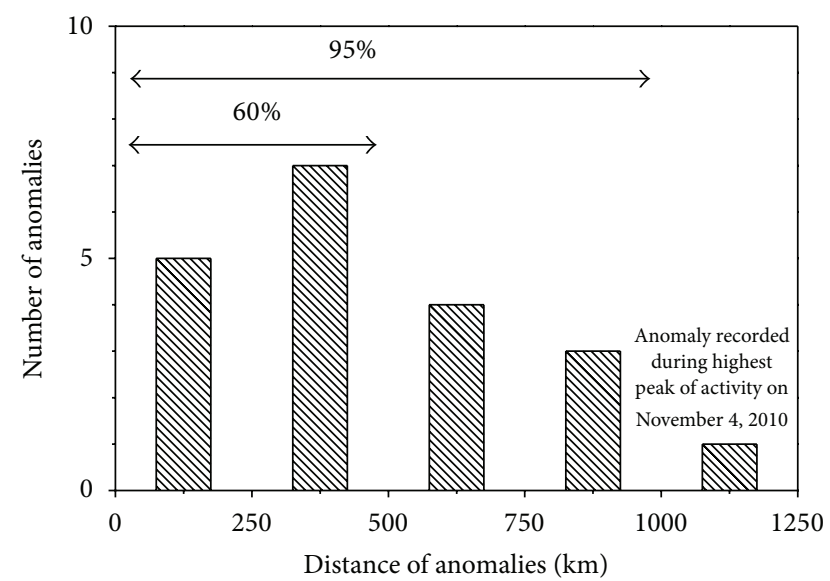

FIGURE 10: Distribution of the ionospheric anomalies versus the distance between the footprint of the satellite and the volcano during Merapi eruption (September 1 to November 30, 2010).

August 2004-December 2010

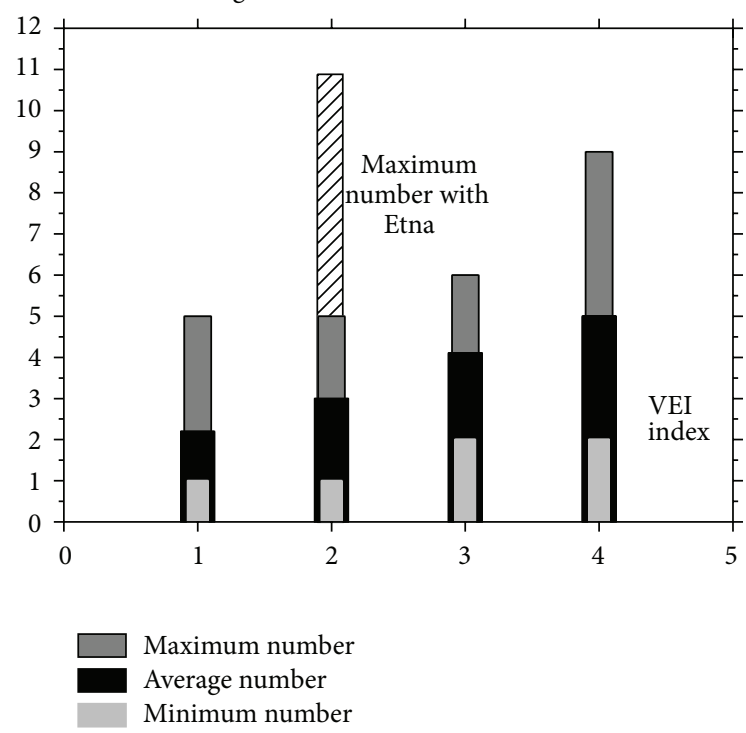

FIGURE 11: Maximum, average, and minimum numbers of anomalies versus the Volcanic Explosivity Index (VEI, http://vulcan.wr.usgs .gov/News/MSH2004/VEI_information.pdf).

related to volcanoes on which explosive activity takes place (see Figure 1). However, the anomalies in the database seem to be independent of the location and the type of the volcanic edifices. On the other hand, the computation of the average number of ionospheric anomalies versus VEI index over the 6.5 years of records shows that the more the strength of the eruption is, (i) the more anomalies in the ionosphere can be observed and (ii) the larger the maximum number of anomalies may occur (Figure 11). Although these results are based on a relatively small database (269 anomalies), the results are coherent and indicate that there is a relationship between the increasing magnitude of a volcanic activity and the number of anomalies in the ionosphere which might be observed between 60 days before an eruption till 15 days after.

\section{Conclusion}

DEMETER mission has offered a unique opportunity to constitute a 6.5-year continuous database composed of several parameters (electric and magnetic fields, ionic and electronic temperatures, and densities) devoted to the monitoring of earthquakes and volcanic eruptions occurring on the Earth, through induced perturbations in the ionosphere.

The study was focused on the identification of signals related to volcanic eruptions in the time window of 60 days before an eruptive event till 15 days after, corresponding to the period during which seismicity and ground deformations may rise up quickly as well as gas releases, thermal anomalies, and electromagnetic field variations.

Although the satellite was mainly flying at $660 \mathrm{~km}$ in altitude at a velocity of $7.4 \mathrm{~km} / \mathrm{sec}$, performing $\sim 14$ orbits per day with a spatial shift of the trajectory of $2860 \mathrm{~km}$ at the equator, it was possible to look for perturbations in the ionosphere in the time windows of 244 seconds corresponding to the flights over impeding eruptive centres.

From August 2004 to December 2010, 73 volcanoes have entered into eruptions between latitudes $50^{\circ} \mathrm{S}$ and $50^{\circ} \mathrm{N}$. It was possible to find 58 volcanoes for which anomalies appeared in the ionosphere. The 269 anomalies, related to 89 eruptions, were classified in 5 types. Electrostatic disturbances (type 1) and electromagnetic discharges (type 2) were the most representative anomalies with an amount of $23.4 \%$ and $69.5 \%$, respectively. In the 75 days bracketing the eruptions, the maximum number of type 1 and 2 anomalies appears in the time window of 30 days to 15 days before the onset of the surface activity. This period of time seems to correspond to the transition between a mechanical fatigue period and a dynamical sequence during which more or less irreversible rupture processes leading to surface activity are engaged. During this period, degassing, thermal fluxes, and electric field generation may be amplified giving rise DEMETER anomalies. The detailed study of October 26, 2010, Merapi eruption clearly emphasizes the general results obtained during the life of DEMETER satellite. Ionospheric anomalies appear during the two months preceding this 100 -year big eruption, and the anomalies seem to be related to transient $\mathrm{SO}_{2}$ gas releases. This hypothesis should be more carefully investigated in the future when new satellites will be available.

More than 1300 volcanoes have erupted during the last 10,000 years [68]. About $12 \%$ of the world's population are living on or nearby about 550 active and dangerous volcanic complexes $[62,69]$. Less than $1 / 4$ of them can be considered as sufficiently monitored by land networks for detecting a renewal of their activity. Nevertheless, the human and economical costs of volcanic eruptions might be very high to support. As an example, the cost of the only disruption of the air traffic due to the Eyjafjallajökull eruption in 2010 was estimated to be $\$ 250$ million per day [70]. If one might suggest that the costs of a medium size monitoring network on land and of a microsatellite dedicated to the observation of the Earth, as DEMETER for instance, are about $\$ 1$ million and $\$ 10$ million, respectively, it clearly appears that the promising past and present day results should lead to develop 
fundamental studies on the appearance of precursory signals before volcanic eruptions.

\section{Acknowledgments}

The authors greatly thank the French National Spatial Agency (CNES) for promoting advanced researches in the electromagnetic field related to earthquakes and volcanic eruptions. Thanks to the launching of DEMETER microsatellite and to the integration of satellite and ground-based observations, encouraging results are obtained in Natural Hazards Mitigation. The study has also been supported by the IndoFrench Centre for the Promotion of Advanced Research (IFCAR). The authors are immensely grateful to Jean Louis Le Mouël who has always supported DEMETER mission. The authors are also indebted to the Electromagnetic Studies of Earthquakes and Volcanoes (EMSEV) working group for helpful discussions. The authors also express thanks to J. Y. Brochot for his valuable help in getting data from DEMETER mission centre. TOSCA commission did not support this study.

\section{References}

[1] A. C. Frazer-Smith, A. Bernadini, P. R. MC Gill, M. E. Ladd, R. A. Helliwell, and O. G. Villard, "Low-frequency magnetic field measurements near the epicentre of the Ms 7. 1 Loma Prieta earthquake," Geophysical Research Letters, vol. 17, no. 9, pp. 1465-1468, 1990.

[2] M. Hayakawa, R. Kawate, O. A. Molchanov, and K. Yumoto, "Results of ultra-low-frequency magnetic field measurements during the Guam earthquake of 8 August 1993," Geophysical Research Letters, vol. 23, no. 3, pp. 241-244, 1996.

[3] J. Y. Liu, Y. I. Chen, Y. J. Chuo, and H. F. Tsai, "Variations of ionospheric total electron content during the Chi-Chi earthquake," Geophysical Research Letters, vol. 28, no. 7, pp. 1383-1386, 2001.

[4] K. Hattori, "ULF geomagnetic changes associated with large earthquakes," Terrestrial, Atmospheric and Oceanic Sciences, vol. 15, no. 3, pp. 329-360, 2004.

[5] O. A. Molchanov, M. Hayakawa, and V. A. Rafalsky, "Penetration characteristics of electromagnetic emissions from an underground seismic source into the atmosphere, ionosphere, and magnetosphere," Journal of Geophysical Research, vol. 100, no. A2, pp. 1691-1712, 1995.

[6] M. J. S. Johnston, "Review of electric and magnetic fields accompanying seismic and volcanic activity," Surveys in Geophysics, vol. 18 , no. 5, pp. 441-476, 1997.

[7] M. Hayakawa and O. A. Molchanov, Seismoelectromagnetics, TerraPub, Tokyo, Japan, 2003.

[8] P. A. Varotsos, The Physics of Seismic Electric Signals, TerraPub, Tokyo, Japan, 2005.

[9] D. Ouzounov, N. Bryant, T. Logan, S. Pulinets, and P. Taylor, "Satellite thermal IR phenomena associated with some of the major earthquakes in 1999-2003," Physics and Chemistry of the Earth, vol. 31, no. 4-9, pp. 154-163, 2006.

[10] M. Parrot, "Anomalous seismic phenomena: view from space," in Electromagnetic Phenomena Associated with Earthquakes, M. Hayakawa, Ed., pp. 205-233, Transworld Research Network, Trivandrum, India.
[11] S. A. Pulinets, "Physical mechanism of the vertical electric field generation over active tectonic faults," Advances in Space Research, vol. 44, no. 6, pp. 767-773, 2009.

[12] S. Pulinets and D. Ouzounov, "Lithosphere-AtmosphereIonosphere Coupling (LAIC) model-an unified concept for earthquake precursors validation," Journal of Asian Earth Sciences, vol. 41, no. 4-5, pp. 371-382, 2011.

[13] J. N. Thomas, J. J. Love, and M. J. S. Johnston, "On the reported magnetic precursor of the 1989 Loma Prieta earthquake," Physics of the Earth and Planetary Interiors, vol. 173, no. 3-4, pp. 207-215, 2009.

[14] J. Qian, "Regional study of the anomalous change in apparent resistivity before the Tangshan earthquake $(M=7.8,1976)$ in China," Pure and Applied Geophysics, vol. 122, no. 6, pp. 901920, 1984.

[15] X. B. Du, N. Li, Q. Ye, Z. H. Ma, and R. Yan, "A possible reason for the anisotropic changes in apparent resistivity near the focal region of strong earthquake," Chinese Journal of Geophysics, vol. 50, no. 6, pp. 1555-1565, 2007.

[16] Y. Sasai, J. Zlotnicki, Y. Nishida et al., "Electromagnetic monitoring of miyake-jima volcano, izu-bonin arc, Japan: a preliminary report," Journal of Geomagnetism and Geoelectricity, vol. 49, no. 11-12, pp. 1293-1316, 1997.

[17] M. J. S. Johnston, Y. Sasai, G. D. Egbert, and R. J. Mueller, "Seismomagnetic effects from the long-awaited 28 September 2004 M 6.0 Parkfield earthquake," Bulletin of the Seismological Society of America, vol. 96, no. 4 B, pp. S206-S220, 2006.

[18] D. Ouzounov, S. Pulinets, A. Romanov et al., "Atmosphereionosphere response to the M9 Tohoku earthquake revealed by multi-instrument space-borne and ground observations: preliminary results," Earthquake Science, vol. 24, no. 6, pp. 557564, 2011.

[19] K. Heki, "Ionospheric electron enhancement preceding the 2011 Tohoku-Oki earthquake," Geophysical Research Letters, vol. 38, no. 17, 2011.

[20] L. M. He, L. X. Wu, S. Pulinets, S. J. Liu, and F. Yang, "A nonlinear background removal method for seismo-ionospheric anomaly analysis under a complex solar activity scenario: a case study of the M9.0 Tohoku earthquake," Advances in Space Research, vol. 50, no. 2, pp. 211-220, 2012.

[21] M. Akhoondzadeh, "Anomalous TEC variations associated with the powerful Tohoku earthquake of 11 March 2011," Natural Hazards and Earth System Sciences, vol. 12, no. 5, pp. 1453-1462, 2012.

[22] J. Y. Liu, Y. I. Chen, C. H. Chen et al., "Seismoionospheric GPS total electron content anomalies observed before the 12 May 2008 Mw7.9 Wenchuan earthquake," Journal of Geophysical Research A, vol. 114, no. 4, Article ID A04320, 2009.

[23] S. Kon, M. Nishihashi, and K. Hattori, "Ionospheric anomalies possibly associated with $M \geq 6.0$ earthquakes in the Japan area during 1998-2010: case studies and statistical study," Journal of Asian Earth Sciences, vol. 41, no. 4-5, pp. 410-420, 2011.

[24] T. Yukutake, "An overview of the eruptions of Oshima Volcano, Izu, 1986-1987 from the geomagnetic and geoelectric standpoints," Journal of Geomagnetism \& Geoelectricity, vol. 42, no. 3, pp. 141-150, 1990.

[25] T. Hashimoto and Y. Tanaka, "A large self-potential anomaly on Unzen volcano, Shimabara Peninsula, Kyushu Island, Japan,” Geophysical Research Letters, vol. 22, no. 3, pp. 191-194, 1995.

[26] J. Zlotnicki, Y. Sasai, J. P. Toutain et al., "Electromagnetic and geochemical methods applied to investigations of hydrothermal/volcanic unrests: examples of Taal (Philippines) and 
Miyake-jima (Japan) volcanoes," Physics and Chemistry of the Earth, vol. 34, no. 6-7, pp. 394-408, 2009.

[27] S. Uyeda, M. Hayakawa, T. Nagao et al., "Electric and magnetic phenomena observed before the volcano-seismic activity in 2000 in the Izu Island Region, Japan," Proceedings of the National Academy of Sciences of the United States of America, vol. 99, no. 11, pp. 7352-7355, 2002.

[28] S. Byrdina, S. Friedel, J. Wassermann, and J. Zlotnicki, "Selfpotential variations associated with ultra-long-period seismic signals at Merapi volcano," Geophysical Research Letters, vol. 30, no. 22, 2003.

[29] J. Zlotnicki, J. L. Le Mouël, A. Gvishiani et al., "Automatic fuzzylogic recognition of anomalous activity on long geophysical records: application to electric signals associated with the volcanic activity of La Fournaise Volcano (Réunion Island)," Earth and Planetary Science Letters, vol. 234, no. 1-2, pp. 261278, 2005.

[30] R. Napoli, G. Currenti, C. Del Negro, A. Di Stefano, F. Greco, and E. Boschi, "Magnetic features of the magmatic intrusion that occurred in the 2007 eruption at Stromboli Island (Italy)," Bulletin of Volcanology, vol. 73, no. 9, pp. 1311-1322, 2011.

[31] C. Del Negro, G. Currenti, R. Napoli, and A. Vicari, "Volcanomagnetic changes accompanying the onset of the 20022003 eruption of Mt. Etna (Italy)," Earth and Planetary Science Letters, vol. 229, no. 1-2, pp. 1-14, 2004.

[32] Y. Sasai, M. Uyeshima, J. Zlotnicki et al., "Magnetic and electric field observations during the 2000 activity of Miyake-jima volcano, Central Japan," Earth and Planetary Science Letters, vol. 203, no. 2, pp. 769-777, 2002.

[33] M. B. Gokhberg, V. A. Pilipenko, and O. A. Pokhotelov, "Satellite observation of the electromagnetic radiation above the epicentral region of an incipient earthquake," Doklady of the Academy of Sciences of the USSR Earth Sciences Sections, vol. 268, no. 1, pp. 5-7, 1983.

[34] M. Parrot, "Statistical study of ELF/VLF emissions recorded by a low altitude satellite during seismic events," Journal of Geophysical Research, vol. 99, no. A12, pp. 23339-23347, 1994.

[35] V. Tramutoli, G. Di Bello, N. Pergola, and S. Piscitelli, "Robust satellite techniques for remote sensing of seismically active areas," Annali di Geofisica, vol. 44, no. 2, pp. 295-312, 2001.

[36] N. Pergola, F. Marchese, and V. Tramutoli, "Automated detection of thermal features of active volcanoes by means of infrared AVHRR records," Remote Sensing of Environment, vol. 93, no. 3, pp. 311-327, 2004.

[37] F. Nemec, O. Santolík, M. Parrot, and J. J. Berthelier, "Spacecraft observations of electromagnetic perturbations connected with seismic activity," Geophysical Research Letters, vol. 35, no. 5, 2008.

[38] F. Nemec, O. Santolík, and M. Parrot, "Decrease of intensity of ELF/VLF waves observed in the upper ionosphere close to earthquakes: a statistical study," Journal of Geophysical Research, vol. 114, no. A4, 2009.

[39] R. P. Singh, W. Mehdi, R. Gautam, J. Senthil kumar, J. Zlotnicki, and M. Kafatos, "Precursory signals using satellite and ground data associated with the Wenchuan earthquake of 12 may 2008," International Journal of Remote Sensing, vol. 31, no. 13, pp. 33413354, 2010.

[40] K. Cheng and Y. H. Huang, "Ionospheric disturbances observed during the period of Pinatubo eruptions in June 1991," Journal of Geophysical Research, vol. 97, no. A11, pp. 16995-17004, 1992.
[41] A. H. C. de Ragone, A. N. F. de Manzano, A. G. Elias, and M. Z. de Artigas, "Ionospheric effects of volcanic eruptions," Geofisica Internacional, vol. 43, no. 2, pp. 187-192, 2004.

[42] J. Zlotnicki, F. Li, and M. Parrot, "Signals recorded by DEMETER satellite over active volcanoes during the period 2004 August-2007 December," Geophysical Journal International, vol. 183, no. 3, pp. 1332-1347, 2010.

[43] J. J. Berthelier, M. Godefroy, F. Leblanc et al., "ICE, the electric field experiment on DEMETER," Planetary and Space Science, vol. 54, no. 5, pp. 456-471, 2006.

[44] D. Lagoutte, J. Y. Brochot, D. de Carvalho et al., "The DEMETER science mission centre," Planetary and Space Science, vol. 54, no. 5, pp. 428-440, 2006.

[45] J.-P. Lebreton, S. Stverak, P. Travnicek et al., “The ISL langmuir probe experiment processing onboard DEMETER: scientific Objectives, description and first results," Planetary and Space Science, vol. 54, no. 5, pp. 472-486, 2006.

[46] M. Parrot, D. Benoist, J. J. Berthelier et al., “The magnetic field experiment IMSC and its data processing onboard DEMETER: scientific objectives, description and first results," Planetary and Space Science, vol. 54, no. 5, pp. 441-455, 2006.

[47] J. Zlotnicki, J. L. Le Mouël, R. Kanwar et al., "Ground-based electromagnetic studies combined with remote sensing based on DEMETER mission: a way to monitor active faults and volcanoes," Planetary and Space Science, vol. 54, no. 5, pp. 541$557,2006$.

[48] S. R. McNutt, "Seismic monitoring and eruption forecasting of volcanoes: a review of the state-of-the-art and case histories," in Monitoring and Mitigation of Volcano Hazards, R. Scarpa and R. Tilling, Eds., pp. 99-146, Springer, Berlin, Germany, 1996.

[49] C. R. J. Kilburn, "Multiscale fracturing as a key to forecasting volcanic eruptions," Journal of Volcanology and Geothermal Research, vol. 125, no. 3-4, pp. 271-289, 2003.

[50] S. Sarkar, A. K. Gwal, and M. Parrot, "Ionospheric variations observed by the DEMETER satellite in the mid-latitude region during strong earthquakes," Journal of Atmospheric and SolarTerrestrial Physics, vol. 69, no. 13, pp. 1524-1540, 2007.

[51] M. Parrot, J. J. Berthelier, J. P. Lebreton, J. A. Sauvaud, O. Santolik, and J. Blecki, "Examples of unusual ionospheric observations made by the title satellite over seismic regions," Physics and Chemistry of the Earth, vol. 31, no. 4-9, pp. 486-495, 2006.

[52] S. Bhattacharya, S. Sarkar, A. K. Gwal, and M. Parrot, "Satellite and ground-based ULF/ELF emissions observed before Gujarat earthquake in March 2006," Current Science, vol. 93, no. 1, pp. 41-46, 2007.

[53] S. Bhattacharya, S. Sarkar, A. K. Gwal, and M. Parrot, "Observations of ULF/ELF anomalies detected by DEMETER satellite prior to earthquakes," Indian Journal Of Radio \& Space Physics, vol. 36, pp. 103-113, 2007.

[54] Y. Sasai, T. Shimomura, Y. Hamano et al., "Volcanomagnetic effect observed during the 1986 eruption of Izu-Oshima volcano," Journal of Geomagnetism and Geoelectricity, vol. 42, no. 3, pp. 291-317, 1990.

[55] M. Yamamoto, H. Kawakatsu, K. Yomogida, and J. Koyama, "Long-period (12 sec) volcanic tremor observed at Usu 2000 eruption: seismological detection of a deep magma plumbing system," Geophysical Research Letters, vol. 29, no. 9, pp. 43-1, 2002.

[56] S. F. M. Chastin and I. G. Main, "Statistical analysis of daily seismic event rate as a precursor to volcanic eruptions," Geophysical Research Letters, vol. 30, no. 13, 2003. 
[57] S. D. Malone, C. Boyko, and C. S. Weaver, "Seismic precursors to the Mount St. Helens eruptions in 1981 and 1982," Science, vol. 221, no. 4618, pp. 1376-1378, 1983.

[58] A. Ratdomopurbo and G. Poupinet, "An overview of the seismicity of Merapi volcano (Java, Indonesia), 1983-1994," Journal of Volcanology and Geothermal Research, vol. 100, no. 1-4, pp. 193-214, 2000.

[59] C. R. J. Kilburn and P. R. Sammonds, "Maximum warning times for imminent volcanic eruptions," Geophysical Research Letters, vol. 32, no. 24, 2005.

[60] P. Surono, P. Jousset, J. P. M. Boichu et al., "The 2010 explosive eruption of Java's Merapi volcano-a "100-year" event," Journal of Volcanology and Geothermal Research, vol. 241-242, pp. 121135.

[61] B. Voight, "A relation to describe rate-dependent material failure," Science, vol. 243, no. 4888, pp. 200-203, 1989.

[62] W. J. McGuire and C. R. J. Kilburn, "Forecasting volcanic events: some contemporary issues," Geologische Rundschau, vol. 86, no. 2, pp. 439-445, 1997.

[63] S. R. Mc Nutt, "Volcano seismicity," in Encyclopedia of Volcanoes, H. Sigurdson, Ed., pp. 1015-1033, Academic Press, San Diego, Calif, USA, 2000.

[64] T. Menand and S. R. Tait, "A phenomenological model for precursor volcanic eruptions," Nature, vol. 411, no. 6838, pp. 678-680, 2001.

[65] T. A. Mather and R. G. Harisson, "Electrification of volcanic plumes," Surveys in Geophysics, vol. 27, pp. 387-432, 2006.

[66] V. M. Sorokin, "Plasma and electromagnetic effects in the ionosphere related to the dynamics of charged aerosols in the lower atmosphere," Russian Journal of Physical Chemistry B, vol. 1, no. 2, pp. 138-170, 2007.

[67] V. M. Sorokin, A. K. Yaschenko, and M. Hayakawa, "A perturbation of DC electric field caused by light ion adhesion to aerosols during the growth in seismic-related atmospheric radioactivity," Natural Hazards and Earth System Science, vol. 7, no. 1, pp. 155163, 2007.

[68] T. Simkin, L. Siebert, L. McClelland, D. Bridge, C. Newhall, and J. H. Latter, Volcanoes of the World, Hutchinson Ross Publishing, Stroudsburg, Pa, USA, 2nd Ed edition, 1994.

[69] C. Small and T. Naumann, "The global distribution of human population and recent volcanism," Environmental Hazards, vol. 3, no. 3-4, pp. 93-109, 2001.

[70] M. T. Gudmundsson, R. Pedersen, K. Vogfjörd, B. Thorbjarnardóttir, S. Jakobsdóttir, and M. J. Roberts, "Eruptions of Eyjafjallajökull Volcano, Iceland,” Eos, vol. 91, no. 21, pp. 190191, 2010. 

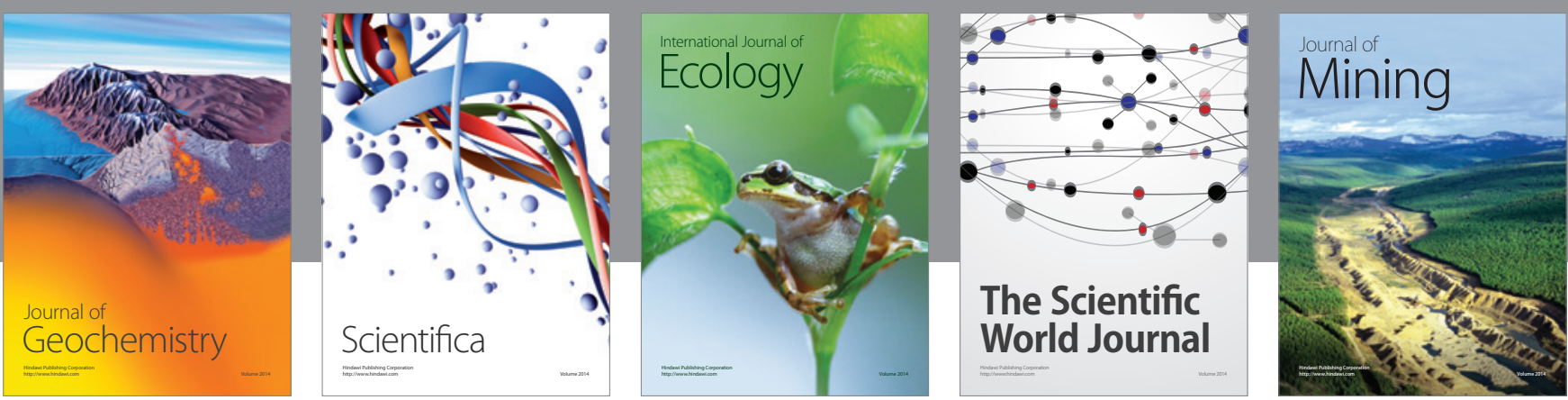

The Scientific World Journal
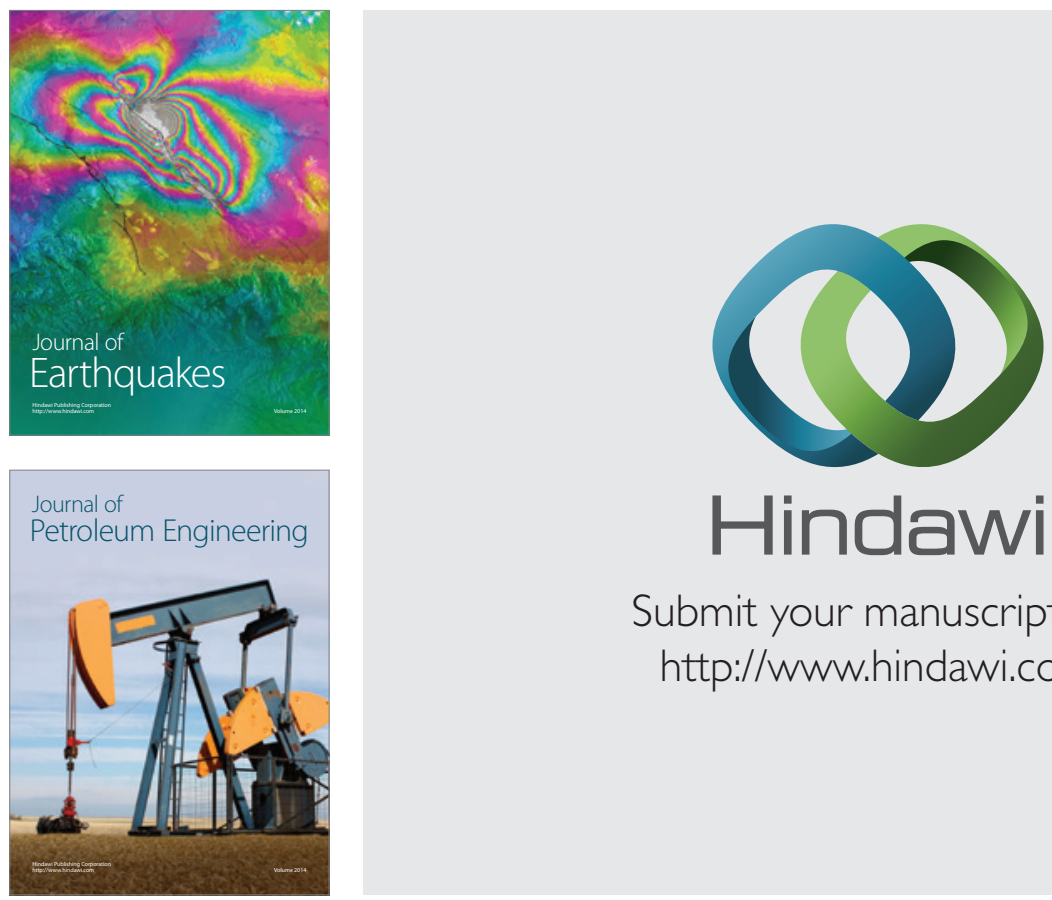

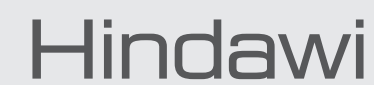

Submit your manuscripts at

http://www.hindawi.com
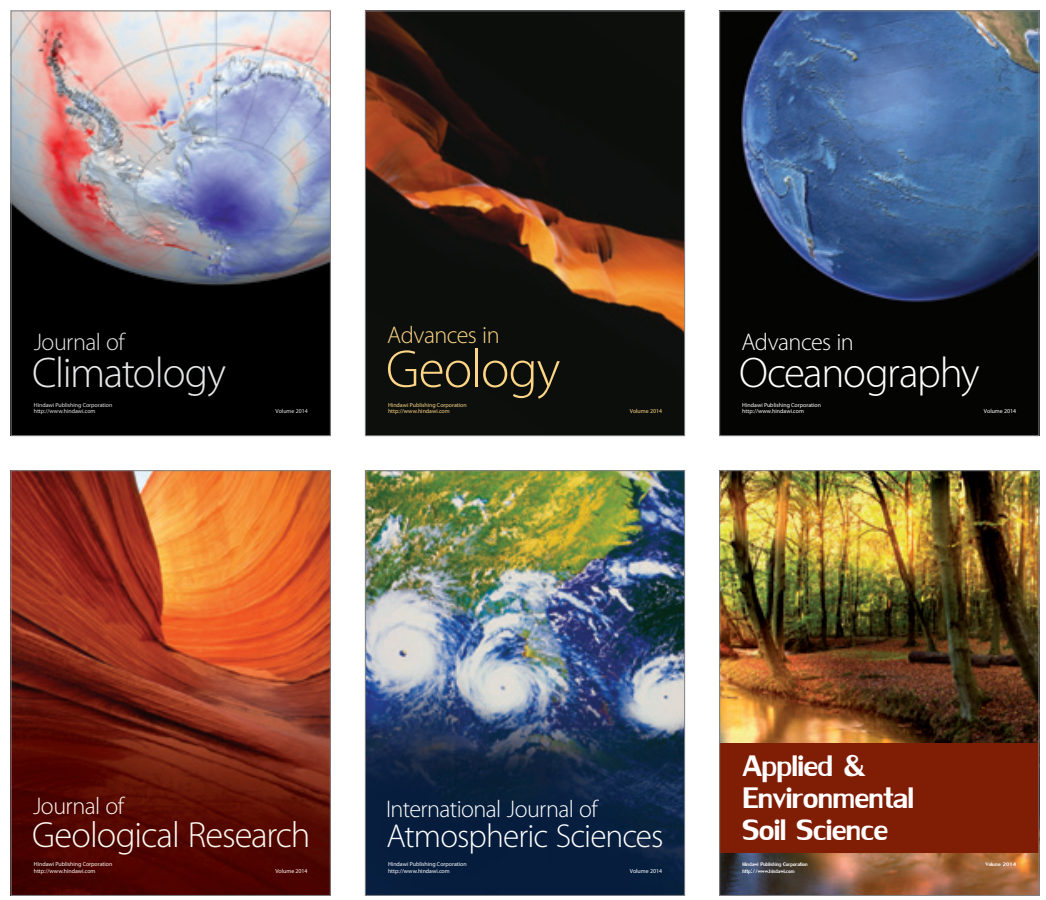
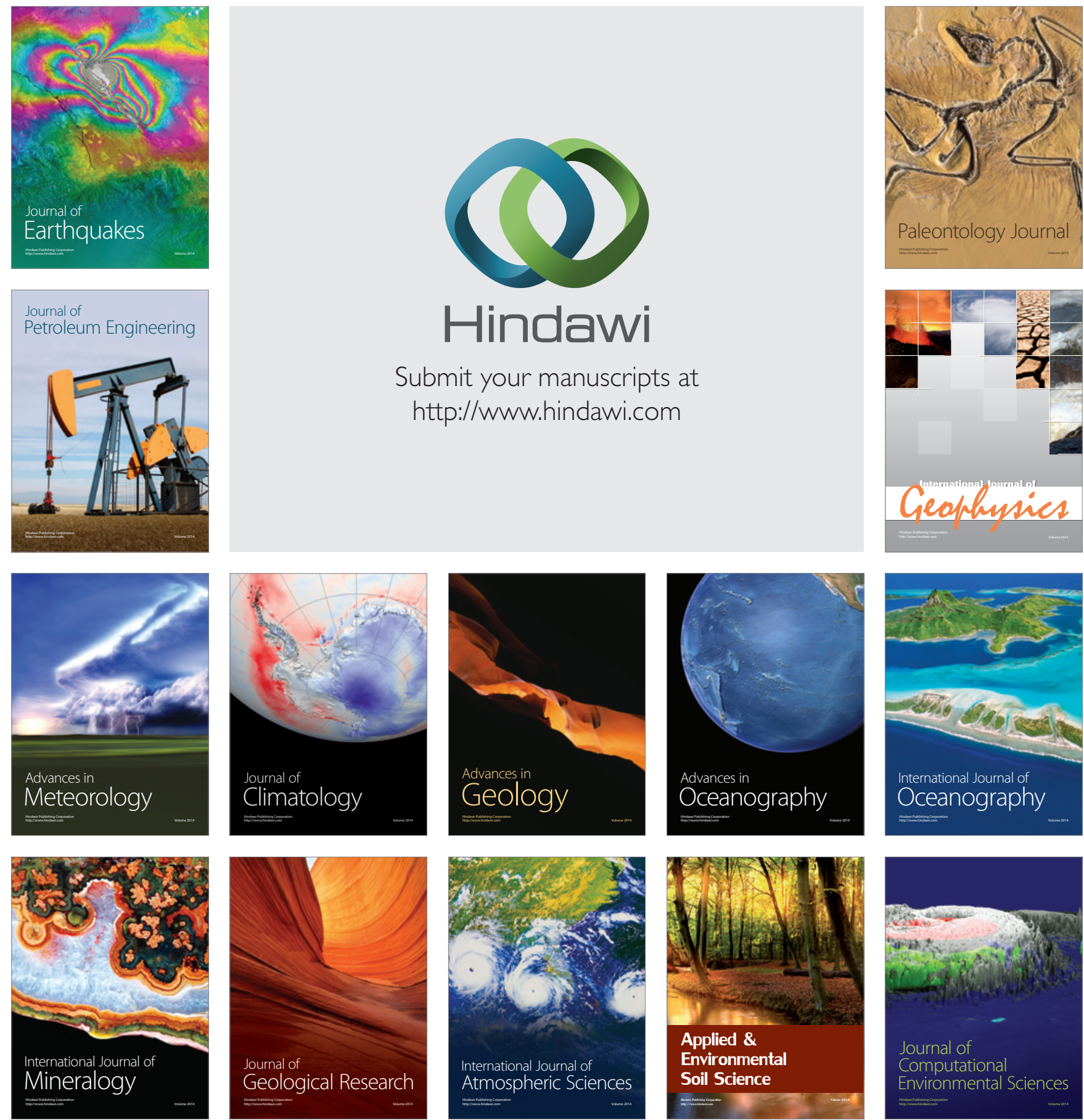